\title{
Low-cost Ca-based composites synthesized by biotemplate method for thermochemical energy storage of concentrated solar power
}

Monica Benitez-Guerrero a,b, Jose Manuel Valverde a,*, Antonio Perejon b,c, Pedro E. Sanchez-Jimenez b, Luis A. Perez-Maqueda b

\author{
a Facultad de Física, Universidad de Sevilla, Avenida Reina Mercedes s/n, 41012 Sevilla, Spain \\ b Instituto de Ciencia de Materiales de Sevilla, C.S.I.C.-Universidad de Sevilla, C. Américo Vespucio n49, 41092 Sevilla, Spain \\ c Facultad de Química, Universidad de Sevilla, Avenida Reina Mercedes s/n, 41012 Sevilla, Spain \\ * Corresponding author. \\ E-mail address: jmillan@us.es (J.M. Valverde).
}

\begin{abstract}
An ever more environmentally conscious society demands the use of green, sustainable and high-efficiency renewable energy resources. However, large-scale energy storage remains a challenge for a deep penetration of power produced from renewables into the grid. The CalciumLooping $(\mathrm{CaL})$ process, based on the reversible carbonation/calcination of $\mathrm{CaO}$, is a promising technology for thermochemical energy storage (TCES) in Concentrated Solar Power (CSP) plants. Natural limestone to be used as $\mathrm{CaO}$ precursor is cheap, non-toxic and abundant. Nevertheless, recent works have shown that carbonation of $\mathrm{CaO}$ derived limestone at optimum conditions for TCES is limited by pore-plugging, which leads to severe deactivation for large enough particles to be employed in practice. In our work, we have synthesized inexpensive $\mathrm{CaO} / \mathrm{SiO} 2$ composites by means of a biotemplate method using rice husk as support. The morphological and compositional features of the biomorphic materials synthesized help improve the CaO multicycle activity under optimum CSP storage conditions and for particles sufficiently large to be managed in practical processes.
\end{abstract}

Keywords: Renewable resources, Energy conversion, Thermochemical energy storage, Calcium looping, Biomorphic composites 


\section{Introduction}

The Calcium-Looping ( $\mathrm{CaL}$ ) process based on the reversible carbonation/calcination reaction of $\mathrm{CaO}$ :

$\mathrm{CaO}_{(\mathrm{s})}+\mathrm{CO}_{2(\mathrm{~g})} \rightleftarrows \mathrm{CaCO}_{3}(\mathrm{~s}) ; \Delta \mathrm{Hr}^{0}=-178 \mathrm{~kJ} \mathrm{~mol}^{-1}$

has been extensively studied in the last years to capture $\mathrm{CO}_{2}$ from fossil fuel-fired power plants [1-3] as originally proposed by Shimizu et al. [4]. In the late 1970s the CaL process was early investigated for thermochemical energy storage (TCES) of concentrated solar power (CSP) $[5,6]$. In the last years most of the works on energy storage in CSP has been focused on molten salts technology [7-10] and redox-based systems [11-13]. The use of the CaL process to this end has not attracted a wide interest until quite recently as it would allow long term storage of massive amounts of energy at low cost and using abundant and nontoxic materials such as limestone [14]. A flow diagram of the integration of the CaL process in CSP plants recently proposed elsewhere [14] built upon a closed $\mathrm{CO}_{2}$ cycle is shown in Fig. 1. It basically consists of a solar calciner, a carbonation reactor, a $\mathrm{CO}_{2}$ compression-storage system, two reservoirs for $\mathrm{CaO}$ and $\mathrm{CaCO}_{3}$ storage and a power unit. After calcination of $\mathrm{CaCO}_{3}$ in the calciner using concentrated solar energy, the sensible heat of $\mathrm{CaO}$ and $\mathrm{CO}_{2}$ is recovered and these products are stored independently. On demand, $\mathrm{CaO}$ and $\mathrm{CO}_{2}$ are circulated into the carbonator wherein heat is released by the exothermic carbonation reaction. This heat is transported by the $\mathrm{CO}_{2}$ in excess to a gas turbine where electricity is generated while the effluent $\mathrm{CO}_{2}$ is sent to storage.

Optimum CaL conditions to obtain the maximum overall efficiency from the CaL-CSP integration involve high temperature carbonation (above $850{ }^{\circ} \mathrm{C}$ ) under high $\mathrm{CO}_{2}$ concentration. Remarkably, these conditions differ from those corresponding for $\mathrm{CO}_{2}$ capture in which calcination is carried out under high $\mathrm{CO}_{2}$ concentration at high temperature (above $900{ }^{\circ} \mathrm{C}$ ) and carbonation occurs at relatively lower temperature (around $650{ }^{\circ} \mathrm{C}$ ) under low $\mathrm{CO}_{2}$ concentration (around 15 vol.\%) [14]. Among calcium oxide based sorbents, natural limestone (nearly $100 \% \mathrm{CaCO} 3$ ) is the most preferable $\mathrm{CaO}$ precursor since it is environmentally friendly, inexpensive, abundant and widely available [15]. However, a major challenge to use limestone is the severe loss of activity of the regenerated $\mathrm{CaO}$ after just a few cycles of carbonation/decarbonation. Deactivation at $\mathrm{CaL}-\mathrm{CO}_{2}$ capture conditions is due to the marked sintering suffered by the $\mathrm{CaO}$ grains under the necessary harsh calcination conditions, which involve high temperatures and high $\mathrm{CO}_{2}$ partial pressure [16]. On the other hand, pore-plugging is a critical limiting mechanism at CaL-CSP storage conditions as carbonation at high temperature and under high $\mathrm{CO}_{2}$ partial pressure is very fast, which makes it likely that the thick $\mathrm{CaCO}_{3}$ layer blocks the inner pores of the $\mathrm{CaO}$ particles $[17,18]$.

In order to avoid deactivation, the use of different additives such as 
$\mathrm{Al}_{2} \mathrm{O}_{3}, \mathrm{La}_{2} \mathrm{O}_{3}, \mathrm{Li}_{2} \mathrm{CO}_{3}, \mathrm{MgO}, \mathrm{SiO}_{2}, \mathrm{TiO}_{2}, \mathrm{Y}_{2} \mathrm{O}_{3}$ and $\mathrm{ZrO}_{2}$ has been investigated in previous works [19-25]. These studies have been mostly focused on the use of the $\mathrm{CaL}$ process for $\mathrm{CO}_{2}$ capture $[2,3,15]$. Taking into account the large scale of the application (typically around 500 tons of raw limestone would be needed in the $\mathrm{CaL}$ process to capture the $\mathrm{CO}_{2}$ released from a commercial coal fired power plant) [26], a compromise between sorbent cost production and its multicycle activity performance is required [27]. Thus, silica is a promising additive as it is not expensive and a wide spread reliable inert material. Nanostructured silica, both in the form of molecular sieves [28] and nanoparticles [29] serves to improve the dispersibility of $\mathrm{CaO}$ agglomerates [29] and mitigate sintering [30], which is attributed to the formation of calcium silicates at high temperatures that confer thermal stability to the $\mathrm{CaO}$ skeleton at the harsh calcination conditions used for $\mathrm{CO}_{2}$ capture [31]. Nonetheless, the synthesis of nanostructured silica from either sol-gel routes or flame synthesis, which is employed in commercially available products such as Aerosil $@$, has a high cost. In contrast, the use of rice husk biomass (a by-product of rice husk industry), as proposed in the present work, is an alternative cost-effective method to produce nanosilica at massive amounts. Hence, rice husk ash has been used as additive to synthesize $\mathrm{CaO}$ sorbents for $\mathrm{CO}_{2}$ capture $[32,33]$. In this sense, several works have been reported on the use of raw rice husk to generate porous $\mathrm{CaO}$ pellets for $\mathrm{CO}_{2}$ capture with improved $\mathrm{CO}_{2}$ sorption performance $[34,35]$.

However, the effect of silica in $\mathrm{SiO}_{2} / \mathrm{CaO}$ mixtures on the activity of $\mathrm{CaO}$ cycled at $\mathrm{CaL}$ conditions for CSP storage remains largely unexplored yet. Recently, the CaL-CSP multicycle performance of a nano- $\mathrm{SiO}_{2} / \mathrm{CaO}$ composite derived by physical mixing of a commercial $\mathrm{SiO}_{2}$ nanopowder and limestone was analyzed by our group [17]. Quite surprisingly, it was found that the presence of nanosilica caused a significant deterioration of the multicycle $\mathrm{CaO}$ activity, in contrast with previous results obtained at $\mathrm{CaL}$ conditions for $\mathrm{CO}_{2}$ capture [30]. The action of nanosilica, by shifting the $\mathrm{CaO}$ mesoporous size distribution to smaller pore sizes, was found to hinder $\mathrm{CaO}$ carbonation by promoting pore-plugging, which is the main limiting factor on $\mathrm{CaO}$ conversion at $\mathrm{CaL}$ conditions for CSP storage.

In the present work, rice husk has been employed to synthesize $\mathrm{CaO} / \mathrm{SiO}_{2}$ composites by a biotemplate route to generate a microstructural porosity in $\mathrm{CaO}$, while at the same time the composites reproduce the micro and nanostructure of the husk. To the best of our knowledge, no further studies have described the use of such kind of composites for thermochemical energy storage of CSP. The multicycle performance of the $\mathrm{CaO} / \mathrm{SiO}_{2}$ composites synthesized in this way is significantly improved as compared to limestone at CaL-CSP conditions. These results are significantly important as they are obtained for particles of size large enough to be used in the practical application in circulating fluidized bed reactors. 


\section{Experimental section}

\subsection{Chemicals and materials}

$\mathrm{Ca}\left(\mathrm{NO}_{3}\right)_{2} \cdot 4 \mathrm{H}_{2} \mathrm{O}$ (Sigma-Aldrich) and raw rice husk (Herba Ricemills S.L.) were used in our work to synthesize $\mathrm{CaO} / \mathrm{SiO}_{2}$ composites. Natural limestone (> $99 \mathrm{wt} \% \mathrm{CaCO}_{3}$ ) from Matagallar quarry in Pedrera (Sevilla, Spain) was also used for the sake of comparison. Two size fractions of this limestone (less than $45 \mu \mathrm{m}$ and 45-160 $\mu \mathrm{m}$ ) were employed (Fig. A1 in Appendix A, Supplementary Content).

\subsection{Synthesis of $\mathrm{CaO} / \mathrm{SiO}_{2}$ composites}

Raw rice husk was pretreated to be used as biotemplate as detailed in Appendix $A$ in order to obtain high purity nanostructured $\mathrm{SiO}_{2}$ of large specific surface area. For this purpose $0.1 \mathrm{~L} \mathrm{Ca}\left(\mathrm{NO}_{3}\right)_{2} \cdot 4 \mathrm{H}_{2} \mathrm{O}$ solutions of 0.5 and $2 \mathrm{M}$ were prepared for the infiltration of $10 \mathrm{~g}$ of as pretreated rice husk. The infiltrating solutions and the pretreated rice husk were maintained at 50 ${ }^{\circ} \mathrm{C}$ during $24 \mathrm{~h}$ under stirring, until infiltration and water evaporation were achieved. Finally, the products were oven-dried at $120^{\circ} \mathrm{C}$ before thermal treatment. The two steps thermal treatment was conducted at the same conditions detailed in the Appendix for the ash synthesis. The nominal compositions of the biotemplated composites are $30 \mathrm{wt} \% \mathrm{SiO}_{2} / 70 \mathrm{wt} \% \mathrm{CaO}$ and $10 \mathrm{wt} \% \mathrm{SiO}_{2} / 90 \mathrm{wt} \% \mathrm{CaO}$ (labeled hereafter as $70 \% \mathrm{CaO}$ and $90 \% \mathrm{CaO}$, respectively).

\subsection{Material characterization}

Compositional analysis was carried out by X-ray fluorescence (XRF) using an Axios PW4400 (PANalytical) instrument and energy-dispersion Xray (EDX) using a Bruker-X Flash-4010 detector. Powder X-ray diffraction (XRD) was performed using a MiniFlex600 (Rigaku) operated with Ni filtered CuKa radiation $(\lambda=1.5406 \AA$ ) at $40 \mathrm{kV}$ and $15 \mathrm{~mA}$ for a scan range $2 \theta=5-$ $90^{\circ}$ at a step rate of $5^{\circ} \min -1$.

Particle size distributions (PSDs) were obtained by laser diffractometry using a Mastersizer 2000 (Malvern). To this end, the samples were previously dispersed in 2-propanol (as recommended for Ca-based materials according to ISO 14887 [36]) and sonicated for $30 \mathrm{~s}$ to loose particle agglomerates.

Nitrogen adsorption-desorption isotherms at $77 \mathrm{~K}$ were acquired by means of a TriStar II 3020 (Micromeritics) instrument. The samples were degassed at $150{ }^{\circ} \mathrm{C}$ for $2 \mathrm{~h}$. Specific surface area (SBET) was calculated using the BET equation [37]. Total pore volume (Vsp) was determined from the amount of gas adsorbed at a $\mathrm{P} / \mathrm{P}_{0}$ value of 0.97 . Mesopore distributions were derived by the $\mathrm{BJH}$ method applied to the adsorption branch of the 
isotherms [38]. The average pore sizes ( $w p$ and $\mathrm{wp}_{\mathrm{BJH}}$ ) were determined by approximating the pore geometry to a cylinder.

Scanning Electron Microscopy (SEM) micrographs and compositional EDX mapping were acquired using a Hitachi S4800 FEG microscope on goldsputtered samples.

Transmission Electron Microscopy (TEM) and High-Angle Annular Dark-Field Scanning Transmission Electron Microscopy (HAADF-STEM) micrographs were registered using a Talos F200S FEG microscope (FEI company) in which the powder samples were deposited on copper grids.

\subsection{Calcium looping (CaL) multicycle conversion}

CaL multicycle tests were carried out using a Q5000IR thermogravimetric analyzer (TA Instruments), which is provided with a high sensitivity balance $(<0.1 \mu \mathrm{g})$ and a furnace heated by IR halogen lamps that allow for high heating and cooling rates (up to $300{ }^{\circ} \mathrm{C} \min -1$ ) to be expected under practical conditions. The samples were subjected to CaL conditions leading to high efficiency for TCES of CSP as reported elsewhere [14]. Each run was initiated with a precalcination stage under helium atmosphere from room temperature to the calcination temperature of 725 ${ }^{\circ} \mathrm{C}$, with a heating ramp of $300{ }^{\circ} \mathrm{C}$ min -1 . Afterwards, the temperature was quickly $\left(300{ }^{\circ} \mathrm{C} \mathrm{min-1)}\right.$ increased to $850{ }^{\circ} \mathrm{C}$ for carbonation under pure $\mathrm{CO}_{2}$ for $5 \mathrm{~min}$. Carbonation was followed by a rapid decrease $\left(300^{\circ} \mathrm{C} \mathrm{min}-1\right)$ of temperature to $725^{\circ} \mathrm{C}$ for calcination under pure He during $5 \mathrm{~min}$. In order to simulate the extraction of sensible heat from the solids in a real plant before they are stored, the temperature was decreased (at $100{ }^{\circ} \mathrm{C}$ min -1 ) to $300{ }^{\circ} \mathrm{C}$ and kept there for 2 min under He between the carbonation and calcination stages. A total of 20 carbonation/calcination cycles were run in this way for the $\mathrm{CaO} / \mathrm{SiO}_{2}$ composites and natural limestone. A schematic representation of the procedure is given in Fig. A2.

Additional tests extended up to 50 cycles were carried out in order to analyze the long-term performance of the materials as well as data reproducibility. In the practical application, the material would not be cycled indefinitely. Due to the significant drop of conversion of limestone derived activity after just 20 cycles, a certain amount of material should be periodically purged while fresh limestone is fed into the system to balance out mass. The average number of cycles that a particle undergoes in the $\mathrm{CaL}$ process will depend on the recirculation flow rate of solids between the carbonator and the calciner and the flow rate of fresh limestone introduced [39]. Thus, the analysis of the multicycle activity of the material along a finite number of cycles yields useful information on its performance for practical purposes. 
The multicycle $\mathrm{CaO}$ conversion, $\mathrm{X}_{\mathrm{CaO}}$, for the $\mathrm{CaO} / \mathrm{SiO}_{2}$ composites is calculated as

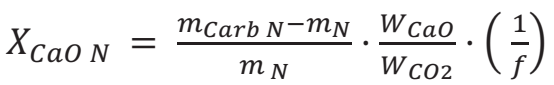

where $m_{N}$ and $m_{\text {carb }} \mathrm{N}$ are the sample masses before and after carbonation at the Nth-cycle and $\mathrm{W}_{\mathrm{CaO}}$ and $\mathrm{W}_{\mathrm{CO} 2}$ are the molar masses of $\mathrm{CaO}$ and $\mathrm{CO}_{2}$, respectively. In Eq. (2), $\mathrm{f}$ is the fraction of $\mathrm{CaO}$ in the mixture. The very small amount of calcium silicates formed, as observed from XRD, is neglected. A more relevant parameter for practical purposes to assess the performance of the samples is the effective conversion, $\mathrm{X}_{\mathrm{ef}} \mathrm{N}$, defined as the ratio of the $\mathrm{CaO}$ mass converted in the carbonation stage of each $\mathrm{N}$-cycle to the total sample mass before carbonation

$X_{\text {ef } N}=\frac{m_{C a r b N}-m_{N}}{m_{N}} \cdot \frac{W_{C a O}}{W_{C O 2}}$

The use of $\mathrm{X}_{\mathrm{ef}}$ takes into account the presence of inert compounds in the composites. Thus, the specific energy released in the carbonation stage per mass unit would be given by $\mathrm{X}_{\mathrm{ef}}$ times $(\Delta \mathrm{Hr} / \mathrm{WCaO})\left(\mathrm{kJ} \mathrm{g}^{-1}\right)$, where $\Delta \mathrm{Hr}^{0}$ is the reaction enthalpy $\left(-178 \mathrm{~kJ} \mathrm{~mol}^{-1}\right)$.

\section{Results and discussion}

The pretreated rice husk (Appendix A), employed as biotemplate to synthesize the $\mathrm{CaO} / \mathrm{SiO}_{2}$ composites, is characterized by a globular external surface and the presence of inner channels (Fig. A3). After combustion of the carbonaceous material, the compositional analysis of the obtained ash reveals that $\mathrm{Si}$ is the main element of the rice husk ash, followed by $\mathrm{Ca}, \mathrm{Mg}$, $\mathrm{Fe}, \mathrm{K}$ and $\mathrm{Mn}$ in minor proportions as well as other trace elements such as $\mathrm{Na}, \mathrm{Al}, \mathrm{S}, \mathrm{P}$ (as shows Table 1 ). In agreement with previous studies [4043], the main ash component generated after thermal treatment of rice husk is nanostructured silica $\left(\mathrm{SiO}_{2}\right)$, which is mainly amorphous in our case as shown in Fig. A5a. The specific surface area of the obtained ash is significantly high, $\mathrm{S}_{\mathrm{BET}}=218 \mathrm{~m}^{2} \mathrm{~g}^{-1}$ as well as the corresponding pore volume, $V p=0.35 \mathrm{~cm}^{3} \mathrm{~g}^{-1}$. The typical pore size is about $3 \mathrm{~nm}$ as observed in Fig. A5b. These values are similar to data reported elsewhere [40]. SEM micrographs in Fig. A6 show that the ash replicates the microstructure of rice husk with a shrinkage factor due to the loss of biomass. SEM analysis on the rice husk ash shows a porous structure in which the bulbous forms and channels observed in the raw rice husk are still clearly identified. The nanoparticles that compose the whole structure, mainly amorphous silica, 
have been analyzed by HRTEM. The size of these nanoparticles is around 10-40 nm, which is similar to the size of the intraparticle pores (Fig. A7).

For infiltration a $\mathrm{Ca}\left(\mathrm{NO}_{3}\right)_{2} \cdot 4 \mathrm{H}_{2} \mathrm{O}$ solution is employed to fill the pores of the biotemplate matrix up to cover completely the inner and outer surface of the pretreated rice husk. During the first step of the thermal treatment, the infiltrated mixture is heated up to $600{ }^{\circ} \mathrm{C}$ in nitrogen. Water from the inorganic salt and the cellulosic material is progressively released until about $200{ }^{\circ} \mathrm{C}$. $\mathrm{Ca}\left(\mathrm{NO}_{3}\right)_{2}$ melts at $560{ }^{\circ} \mathrm{C}$ and subsequent decomposition $\left(2 \mathrm{Ca}\left(\mathrm{NO}_{3}\right)_{2} \rightarrow 2 \mathrm{CaO}+\mathrm{O}_{2}+4 \mathrm{NO}_{2}\right.$ ) occurs in the molten phase [44]. A mixture of the carbonaceous skeleton and inorganic material, mainly amorphous $\mathrm{CaO}$ and $\mathrm{SiO} 2$, is produced after this stage. In a second step, combustion of the carbonaceous material takes place at $600{ }^{\circ} \mathrm{C}$ under air. $\mathrm{CO}_{2}$ and $\mathrm{H}_{2} \mathrm{O}$ generated react with the $\mathrm{CaO}$ particles to form $\mathrm{CaCO}_{3}$ and $\mathrm{Ca}(\mathrm{OH})_{2}$ as observed from XRD for both composites (Fig. A8). Arguably an intermediate specie $\mathrm{Ca}-(\mathrm{OH})$ * that could be formed in amorphous state could quickly react with the $\mathrm{CO}_{2}$ from the combustion of the rice husk char to form the carbonate. The broad amorphous peak at $2 \theta=15-30^{\circ}$ could be attributed to the presence of still a significant amount of amorphous $\mathrm{SiO}_{2}$ in the composite of lower $\mathrm{CaO}$ content (70\%CaO composite).

After thermal treatment, the synthesized inorganic composites replicate the morphology of rice husk as observed in the SEM micrographs of the composites derived with different $\mathrm{CaO}$ load: $70 \% \mathrm{CaO}$ (Fig. 2a and b) and $90 \% \mathrm{CaO}$ (Fig. 2c and d). The composite with smaller $\mathrm{CaO}$ load is characterized by a porous morphology, with $\mathrm{CaCO}_{3}$ loose particles and some fragments rich in $\mathrm{SiO}_{2}$ as obtained from the EDX analysis. On the other hand, the composite with higher $\mathrm{CaO}$ content presents a thicker and compact surface, showing a better replica of the template. These observations are also supported by the porosity results obtained by nitrogen adsorption-desorption isotherms (Table 2). Accordingly, the $70 \% \mathrm{CaO}$ composite has a $\mathrm{S}_{\mathrm{BET}}$ value of $25 \mathrm{~m}^{2} \mathrm{~g}^{-1}$ whereas the $90 \% \mathrm{CaO}$ composite $\mathrm{S}_{\mathrm{BET}}$ value is close to $7 \mathrm{~m}^{2} \mathrm{~g}^{-1}$. The larger pore volume of the $70 \% \mathrm{CaO}$ composite is reflected in its $\mathrm{BJH}$ distribution, which peaks at $6 \mathrm{~nm}$ (Fig. 3a). These microstructural features are consistent with the ranges of particle size measured by laser diffractometry for both composites (PSDs are shown in Fig. 3b). Thus, a reduced agglomeration of the particles of the $70 \% \mathrm{CaO}$ sample leads to lower particle sizes $(1-100 \mu \mathrm{m})$ as compared to the larger compact $90 \% \mathrm{CaO}$ composite particles $(1-1000 \mu \mathrm{m})$.

HRTEM micrographs of as-prepared composites show that the average size of crystalline domains, corresponding to the main crystalline phase $\mathrm{CaCO}_{3}$, is close to $5-10 \mathrm{~nm}$ for both composites (Figs. A9 and A10). A homogenous distribution of $\mathrm{Ca}$ across the particles of both composites is observed by HAADF-STEM mapping (Figs. A9 and A10) whereas the 
distribution of $\mathrm{Si}$ is determined by the own biologic nature of the parent rice husk [45], which is not directly related to the synthesis process.

Fig. 4 shows the time evolution of sample weight and temperature during the first and 20th carbonation/calcination cycles (under CaLCSP storage conditions) carried out by TGA for the $\mathrm{CaO} / \mathrm{SiO}_{2}$ composites synthesized. As may be seen in Fig. 4, carbonation takes place through two well differentiated phases as widely described in the literature for $\mathrm{CaO}$ based sorbents $[46,47]$. A first fast reaction controlled phase taking place at the surface of the $\mathrm{CaO}$ grains is followed by a much slower solid-state diffusion controlled phase which is limited by the counter-current diffusion of inward $\mathrm{CO}_{3}{ }^{2-}$ anion groups and outward $\mathrm{O}^{2-}$ anions across the $\mathrm{CaCO}_{3}$ product layer $[48,49]$. As observed in previous works $[18,50]$, the fast reaction-controlled phase is the main contribution to the overall carbonation along all cycles under CaL-CSP storage conditions. In these CaL conditions, which involve carbonation under high $\mathrm{CO}_{2}$ concentration and high temperature, the reaction controlled fast regime occurring at the surface of the particles is greatly promoted as compared to the solid-state diffusion controlled stage [26].

Fig. 4a shows that $\mathrm{CaO}$ conversion in the first carbonation stage is very similar for both composites (70\% and $90 \% \mathrm{CaO})$. However, the composite with higher $\mathrm{SiO}_{2}$ content $(70 \% \mathrm{CaO})$ is carbonated to a higher level at the 20th cycle (Fig. 4b). Data on the multicycle $\mathrm{CaO}$ conversion $\mathrm{X}_{\mathrm{CaO}}$ and effective conversion Xef (ratio of $\mathrm{CaO}$ converted to total weight of the sorbent including inert $\mathrm{SiO}_{2}$ ) are plotted in Fig. 5. For comparison, data are plotted also on the multicycle conversion measured for natural limestone derived $\mathrm{CaO}$ (lime) reported elsewhere [18]. Data for extended tests up to 50 cycles are shown in Fig. 6, which demonstrates data reproducibility and further confirms the slower decay of conversion for both $70 \% \mathrm{CaO}$ and $90 \% \mathrm{CaO}$ composites compared to limestone. After 50 cycles, the effective conversion of the $70 \% \mathrm{CaO}$ composite is kept slightly higher than the $90 \% \mathrm{CaO}$ composite.

In contrast with the behavior exhibited by the composites, lime conversion suffers a severe drop after just a few cycles due to pore plugging [18]. As discussed in our previous work [18], the relatively low calcination temperature in these $\mathrm{CaL}$ conditions leads to a highly porous $\mathrm{CaO}$ skeleton which is blocked by the thick $\mathrm{CaCO}_{3}$ layer quickly built upon the particle's surface during carbonation at high temperature and under high $\mathrm{CO}_{2}$ concentration as may be inferred from the SEM pictures in Fig. 7. This micrograph of the cycled limestone sample after being subjected to the CaL cycles (ending in calcination) show a sintered $\mathrm{CaO}$ layer on the surface of the particles whereas inner parts becoming exposed by particle fracturing exhibit a porous $\mathrm{CaO}$ skeleton, which has arguably not intervened in the carbonation reaction during the cycles. In contrast with the behavior of limestone, Fig. 5 shows that higher conversion values are obtained for the $\mathrm{CaO} / \mathrm{SiO}_{2}$ composites with particles much larger (Fig. 3) than this critical 
value $(\sim 45 \mu \mathrm{m})$ for limestone. These results indicate that pore-plugging is not a limiting factor for carbonation of the $\mathrm{CaO} / \mathrm{SiO}_{2}$ composites. This may be specifically attributed to the novel synthesis method employed as previous results demonstrated that pore-plugging did hinder carbonation of $\mathrm{CaO} / \mathrm{SiO}_{2}$ composites prepared by physical mixing [17].

The morphology of the $\mathrm{CaO} / \mathrm{SiO}_{2}$ composites after being subjected to the CaL cycles is illustrated by the SEM pictures shown in Fig. 8. These SEM micrographs evidence some differences between the $70 \% \mathrm{CaO}$ and $90 \% \mathrm{CaO}$ cycled samples. After the $20 \mathrm{CaL}$ cycles, the composite with higher $\mathrm{SiO}_{2}$ content maintains a foamy surface structure, with small pores and visible $\mathrm{SiO}_{2}$ plates (Figs. $8 \mathrm{a}$ and 9 ). On the contrary, the surface of the $90 \% \mathrm{CaO}$ composite is apparently more compact with relatively larger pores of several tens microns size. Arguably, the porous structure of the $70 \% \mathrm{CaO}$ composite and the deep cavities formed between the $\mathrm{SiO}_{2}$ plates and $\mathrm{CaO}$ grains would facilitate the diffusion of $\mathrm{CO}_{2}$ into the inner pores during carbonation, thus circumventing pore-plugging. This characteristic morphological structure would lead to a better multicycle performance of the composite with the lower $\mathrm{CaO}$ content. In addition, the compositional mapping reveals that $\mathrm{Si}$ is present not only on the external surface (Fig. 9) but also in the inner walls that mimic rice husk as observed in Fig. A11 (Appendix). The higher $\mathrm{CaO}$ load of the $90 \% \mathrm{CaO}$ composite and the limited EDX resolution could explain why silicon is hidden in the corresponding compositional mapping (Fig. A12). Nonetheless, the distribution of $\mathrm{SiO}_{2}$ in the grains at the nanoscopic level for both composites is demonstrated by the HAADF-STEM compositional images (Figs. 10 and A13).

HRTEM micrographs (Figs. 10 and A13) of the samples after being cycled show the presence of wide crystalline domains, which can be attributed to the main $\mathrm{CaCO}_{3}$ and $\mathrm{CaO}$ phases. $\mathrm{SiO}_{2}$ is maintained in an amorphous phase after 20 cycles for both composites (no crystalline $\mathrm{SiO}_{2}$ phase has been detected by XRD). In addition to $\mathrm{CaCO}_{3}$ and $\mathrm{CaO}$, the formation of calcium silicate $\left(\mathrm{CaSiO}_{3}\right)$ and calcium orthosilicate $\left(\mathrm{Ca}_{2} \mathrm{SiO}_{4}\right)$ has been detected by XRD although just by a small amount as inferred from the rather small intensity of their reflection peaks (Fig. 11). The thermally stable and well distributed amorphous silica and the formation of these silicate compounds would serve also to counteract grain sintering due to their high melting point.

In brief, the importance of the work here presented lies mostly on the simplicity of manufacture of $\mathrm{CaO} / \mathrm{SiO}_{2}$ composites with an acceptable multicycle stability under the CaL-CSP storage conditions analyzed, comprising finely dispersed inert phase and particle sizes useful for practical applications in circulating fluidized beds.

Since the final purpose of the composites synthesized is to store energy it is relevant to estimate the energy density of these composites and to compare it with that of the $\mathrm{CaCO}_{3} / \mathrm{CaO}$ system in order to assess the 
suitability of these materials in solar plants. A definition of gravimetric energy density, Dm (MJ kg-1) is given by Pardo et al. [51], expressed as

$D_{m}=\frac{Q}{\sum m_{\text {out }}}$

where $\mathrm{Q}$ is the stored thermal energy (MJ) and $\Sigma \mathrm{m}_{\text {out }}$ is the total material mass $(\mathrm{kg})$ leaving the calciner, that is, the calcination products $\left(\mathrm{CaO}, \mathrm{CO}_{2}\right.$ and the inert material, $\mathrm{SiO}_{2}$ in our case) from which the chemical and calorific energy will be released when needed. Dm can be thus calculated as the sum of the calcination enthalpy and the sensible heat required to raise the temperature of the material entering to the calciner from room temperature to the reaction temperature (calcination temperature):

$D_{m}=\frac{m_{i n} \Delta H_{r}+\sum_{i} m_{i} \int_{\text {Tin }}^{T c a l} C_{p, i} d T}{\sum m_{\text {out }}}$

where $\min$ is the reactive material mass at the entrance of the calciner $(\mathrm{kg})$, i.e. $\mathrm{CaCO}_{3}, \Delta \mathrm{Hr}$ is the reaction enthalpy $(\mathrm{MJ} \mathrm{kg}-1), \mathrm{Cp}, \mathrm{i}$ is the specific heat of each component $(\mathrm{MJ} \mathrm{kg}-1 \mathrm{~K}-1)$, that is, $\mathrm{CaCO}_{3}$, inert material $\left(\mathrm{SiO}_{2}\right)$, and unreacted $\mathrm{CaO}$ if any. Tcal is the calcination temperature and Tin the temperature of the solids entering to the calciner. Thus, from Eq. (5), the gravimetric energy densities can be inferred knowing the mass fraction of inert material (\%SiO2) and reactive material $\left(\% \mathrm{CaCO}_{3}\right)$ in the synthetized composites, the variation of $\mathrm{Cp}$ with temperature for $\mathrm{CaCO}_{3}$ and $\mathrm{SiO}_{2}$ between the inlet and calcination temperatures for the first cycle (25 and $725^{\circ} \mathrm{C}$ ) [52]. The results of the calculations yield Dm values of 2.55, 2.44 and $2.20 \mathrm{MJ} \mathrm{kg}-1$ for pure $\mathrm{CaCO}_{3}, 10 \mathrm{wt} \% \mathrm{SiO}_{2} / 90 \mathrm{wt} \% \mathrm{CaO}$ and $30 \mathrm{wt} \% \mathrm{SiO}_{2} / 70 \mathrm{wt} \% \mathrm{CaO}$ composites, respectively. A fraction of $\mathrm{SiO} 2$ of $6 \mathrm{wt} \%$ in the reactive carbonate leads to a reduction by $4 \%$ of the Dm value, whereas the presence of $19 \mathrm{wt} \%$ of $\mathrm{SiO}_{2}$ yields a reduction close to $13 \%$. Note that the slight variation of $\mathrm{Cp}$ with temperature does not influence notably the values of energy density in the low temperature range. Thus, for the subsequent cycles carried out using $300{ }^{\circ} \mathrm{C}$ as inlet temperature in the intermediate stage (in order to simulate the extraction of sensible heat of solids) and $725^{\circ} \mathrm{C}$ as calcination temperature, the energy density values can be estimated as 2.28, 2.17 and 1.94 for $\mathrm{CaCO}_{3}, 90 \% \mathrm{CaO}$ and $70 \% \mathrm{CaO}$ samples, respectively. However, the higher effective conversion and multicycle stability of theses composites compared to the limestone with equivalent particle sizes, could compensate a lower energy density. From a techno-economic point of view these results should be considered for 
further research to analyze in depth the advantages of using this kind of $\mathrm{CaO} / \mathrm{SiO}_{2}$ composites in practice.

\section{Conclusions}

This work reports the synthesis of porous $\mathrm{CaO} / \mathrm{SiO}_{2}$ composites by biotemplate route using rice husk and calcium nitrate with the purpose of achieving highly stable $\mathrm{CaO}$ precursors for thermochemical energy storage (TCES) of concentrated solar power (CSP) via the Calcium Looping (CaL) process. CaL conditions for CSP storage would involve carbonation under high $\mathrm{CO}_{2}$ partial pressure at high temperature and calcination at moderate temperature. Such conditions promote $\mathrm{CaO}$ pore-plugging, which hinders the multicycle activity of limestone derived $\mathrm{CaO}$ for particles sufficiently large to be employed in practice. The use of nanosilica as a biotemplate serves to enhance $\mathrm{CaO}$ thermal stability while at the same time is useful to avoid pore-plugging effects as demonstrated on the present work. The composites synthesized with $70 \%$ and $90 \%$ CaO load, respectively, preserve the morphology of rice husk. Both composites exhibit a notably enhanced effective conversion (which takes into account the presence of inert $\mathrm{SiO}_{2}$ ) as compared to limestone with particles larger than $45 \mu \mathrm{m}$. Our study shows that pore plugging is mitigated by the porous structure and uniform $\mathrm{CaO} / \mathrm{SiO}_{2}$ dispersion obtained from the biotemplate synthesis method leading to high values of the multicycle conversion for large enough particles to be captured in cyclonic separators employed in practice.

\section{Acknowledgments}

This work has been supported by the Spanish Government Agency Ministerio de Economia y Competitividad (MINECO-FEDER funds, contracts CTQ2014-52763-C2, CTQ2017-83602-C2). The authors sincerely acknowledge Herba Ricemills, Omya Clariana and Segura S.L. companies for supplying the materials used in the present study. AP thanks financial support from VI PPIT-US and VPPI-US for his current contract. We acknowledge the Microscopy service of the Innovation, Technology and Research Center of the University of Seville (CITIUS) and the Characterization services of the Institute of Materials Science of Seville (ICMS).

\section{References}

[1] Blamey J, Anthony EJ, Wang J, Fennell PS. The calcium looping cycle for largescale CO2 capture. Prog Energy Combust Sci 2010;36(2):260-79.

[2] Kierzkowska AM, Pacciani R, Müller CR. CaO-based CO2 sorbents: from fundamentals to the development of new, highly effective materials. ChemSusChem 
$2013 ; 6(7): 1130-48$.

[3] Valverde JM. Ca-based synthetic materials with enhanced $\mathrm{CO} 2$ capture efficiency. J Mater Chem A 2013;1(3):447-68.

[4] Shimizu T, Hirama T, Hosoda H, Kitano K, Inagaki M, Tejima K. A twin fluid-bed reactor for removal of $\mathrm{CO} 2$ from combustion processes. Chem Eng Res Des 1999;77(1):62-8.

[5] Barker R. The reactivity of calcium oxide towards carbon dioxide and its use for energy storage. J Appl Chem Biotech 1974;24(4-5):221-7.

[6] Flamant G, Hernandez D, Bonet C, Traverse J-P. Experimental aspects of the thermochemical conversion of solar energy; Decarbonation of CaCO3. Sol Energy 1980;24(4):385-95.

[7] Peng Q, Yang X, Ding J, Wei X, Yang J. Design of new molten salt thermal energy storage material for solar thermal power plant. Appl Energy 2013;112:6829.

[8] Fernández AG, Ushak S, Galleguillos H, Pérez FJ. Development of new molten salts with LiNO3 and $\mathrm{Ca}(\mathrm{NO} 3) 2$ for energy storage in CSP plants. Appl Energy 2014;119:131-40.

[9] Vignarooban K, Xu X, Arvay A, Hsu K, Kannan AM. Heat transfer fluids for concentrating solar power systems - a review. Appl Energy 2015;146:383-96.

[10] Zhao BC, Cheng MS, Liu C, Dai ZM. Cyclic thermal characterization of a molten-salt packed-bed thermal energy storage for concentrating solar power. Appl Energy 2017;195:761-73.

[11] Albrecht KJ, Jackson GS, Braun RJ. Thermodynamically consistent modeling of redox-stable perovskite oxides for thermochemical energy conversion and storage.

Appl Energy 2016;165:285-96.

[12] Cabeza LF, Solé A, Fontanet X, Barreneche C, Jové A, Gallas M, et al. Thermochemical energy storage by consecutive reactions for higher efficient concentrated solar power plants (CSP): proof of concept. Appl Energy 2017; 185(Part 1):836-45.

[13] Tescari S, Singh A, Agrafiotis C, de Oliveira L, Breuer S, Schlögl-Knothe B, et al. Experimental evaluation of a pilot-scale thermochemical storage system for a concentrated solar power plant. Appl Energy 2017;189:66-75.

[14] Chacartegui R, Alovisio A, Ortiz C, Valverde JM, Verda V, Becerra JA.

Thermochemical energy storage of concentrated solar power by integration of the calcium looping process and a CO2 power cycle. Appl Energy 2016;173:589-605.

[15] Erans M, Manovic V, Anthony EJ. Calcium looping sorbents for CO2 capture. Appl Energy 2016;180:722-42.

[16] Stanmore BR, Gilot P. Review-calcination and carbonation of limestone during thermal cycling for CO2 sequestration. Fuel Process Technol 2005;86(16):1707-43.

[17] Valverde JM, Barea-López M, Perejón A, Sanchez-Jimenez PE, Perez-Maqueda LA. Thermochemical energy storage for concentrated solar power using natural limestone: thermal pretreatment and nanosilica addition. Energy Fuels 2017.

[18] Benitez-Guerrero M, Sarrion B, Perejon A, Sanchez-Jimenez PE, PerezMaqueda LA, Valverde JM. Large-scale high-temperature solar energy storage using natural minerals. Sol Energy Mater Sol Cells 2017;168:14-21.

[19] Albrecht KO, Wagenbach KS, Satrio JA, Shanks BH, Wheelock TD. Development of a CaO-based $\mathrm{CO} 2$ sorbent with improved cyclic stability. Ind Eng Chem Res 2008;47(20):7841-8.

[20] Li L, King DL, Nie Z, Howard C. Magnesia-stabilized calcium oxide absorbents with improved durability for high temperature $\mathrm{CO} 2$ capture. Ind Eng Chem Res 
2009;48(23):10604-13.

[21] Broda M, Kierzkowska AM, Müller CR. Influence of the calcination and carbonation conditions on the $\mathrm{CO} 2$ uptake of synthetic Ca-based $\mathrm{CO} 2$ sorbents. Environ Sci Technol 2012;46(19):10849-56.

[22] Radfarnia HR, Iliuta MC. Development of zirconium-stabilized calcium oxide absorbent for cyclic high-temperature $\mathrm{CO} 2$ capture. Ind Eng Chem Res 2012; 51(31): 10390-8.

[23] Vieille L, Govin A, Grosseau P. Improvements of calcium oxide based sorbents for multiple CO2 capture cycles. Powder Technol 2012;228:319-23.

[24] Antzara A, Heracleous E, Lemonidou AA. Improving the stability of synthetic CaObased CO2 sorbents by structural promoters. Appl Energy 2015;156:331-43.

[25] Chen H, Zhang P, Duan Y, Zhao C. Reactivity enhancement of calcium based sorbents by doped with metal oxides through the sol-gel process. Appl Energy

2016;162:390-400.

[26] Ortiz C, Valverde JM, Chacartegui R, Benítez-Guerrero M, Perejón A, Romeo LM. The Oxy-CaL process: a novel $\mathrm{CO} 2$ capture system by integrating partial oxycombustion with the Calcium-Looping process. Appl Energy 2017;196:1-17.

[27] Romeo LM, Lara Y, Lisbona P, Martínez A. Economical assessment of competitive enhanced limestones for $\mathrm{CO} 2$ capture cycles in power plants. Fuel Process Technol 2009;90(6):803-11.

[28] Huang $\mathrm{CH}$, Chang KP, Yu CT, Chiang PC, Wang CF. Development of hightemperature $\mathrm{CO} 2$ sorbents made of CaO-based mesoporous silica. Chem Eng J 2010;161(1-2):129-35.

[29] Valverde JM, Perejon A, Perez-Maqueda LA. Enhancement of fast CO2 capture by a nano-SiO2/CaO composite at Ca-looping conditions. Environ Sci Technol 2012;46(11):6401-8.

[30] Sanchez-Jimenez PE, Perez-Maqueda LA, Valverde JM. Nanosilica supported $\mathrm{CaO}$ : a regenerable and mechanically hard $\mathrm{CO} 2$ sorbent at $\mathrm{Ca}-$ looping conditions. Appl Energy 2014;118:92-9.

[31] Wang M, Lee C-G, Ryu C-K. CO2 sorption and desorption efficiency of Ca2SiO4. Int J Hydrogen Energy 2008;33(21):6368-72.

[32] Li Y, Zhao C, Ren Q, Duan L, Chen H, Chen X. Effect of rice husk ash addition on $\mathrm{CO} 2$ capture behavior of calcium-based sorbent during calcium looping cycle. Fuel Process Technol 2009;90(6):825-34.

[33] Chen $\mathrm{H}$, Zhao C, Ren Q. Feasibility of $\mathrm{CO} 2 / \mathrm{SO} 2$ uptake enhancement of calcined limestone modified with rice husk ash during pressurized carbonation. J Environ Manage 2012;93(1):235-44.

[34] Sun J, Liu W, Hu Y, Li M, Yang X, Zhang Y, et al. Structurally improved, coreinshell, CaO-based sorbent pellets for $\mathrm{CO} 2$ capture. Energy Fuels 2015;29(10):6636-44.

[35] Sun J, Liu W, Wang W, Hu Y, Yang X, Chen H, et al. CO2 sorption enhancement of extruded-spheronized $\mathrm{CaO}$-based pellets by sacrificial biomass templating technique. Energy Fuels 2016;30(11):9605-12.

[36] ISO 14887: Sample preparation-dispersing procedures for particles in liquids. In: ISO, editor, Genève; 2000.

[37] Brunauer S, Emmett $\mathrm{PH}$, Teller E. Adsorption of gases in multimolecular layers. J Am Chem Soc 1938;60(2):309-19.

[38] Barrett EP, Joyner LG, Halenda PP. The determination of pore volume and area distributions in porous substances. I. Computations from nitrogen isotherms. J Am Chem Soc $1951 ; 73(1): 373-80$. 
[39] Ortiz C, Chacartegui R, Valverde JM, Becerra JA, Perez-Maqueda LA. A new model of the carbonator reactor in the calcium looping technology for postcombustion CO2 capture. Fuel 2015;160:328-38.

[40] Real C, Alcalá MD, Criado JM. Preparation of silica from rice husks. J Am Ceram Soc 1996;79(8):2012-6.

[41] Kalapathy $U$, Proctor A, Shultz J. A simple method for production of pure silica from rice hull ash. Biores Technol 2000;73(3):257-62.

[42] Della VP, Kühn I, Hotza D. Rice husk ash as an alternate source for active silica production. Mater Lett 2002;57(4):818-21.

[43] Wang W, Martin JC, Fan X, Han A, Luo Z, Sun L. Silica nanoparticles and frameworks from rice husk biomass. ACS Appl Mater Interf 2012;4(2):977-81.

[44] Ettarh C, Galwey AK. A kinetic and mechanistic study of the thermal decomposition of calcium nitrate. Thermochim Acta 1996;288(1):203-19.

[45] Krishnarao RV, Godkhindi MM. Distribution of silica in rice husks and its effect on the formation of silicon carbide. Ceram Int 1992;18(4):243-9.

[46] Barker R. The reversibility of the reaction $\mathrm{CaCO} 3 \rightleftarrows \mathrm{CaO}+\mathrm{CO} 2$. J Appl Chem

Biotech 1973;23(10):733-42.

[47] Grasa G, Murillo R, Alonso M, Abanades JC. Application of the random pore model to the carbonation cyclic reaction. AIChE J 2009;55(5):1246-55.

[48] Bhatia SK, Perlmutter DD. Effect of the product layer on the kinetics of the CO2-lime reaction. AIChE J 1983;29(1):79-86.

[49] Sun Z, Luo S, Qi P, Fan LS. Ionic diffusion through Calcite (CaCO3) layer during the reaction of $\mathrm{CaO}$ and CO2. Chem Eng Sci 2012;81:164-8.

[50] Sarrion B, Valverde JM, Perejon A, Perez-Maqueda L, Sanchez-Jimenez PE. On the multicycle activity of natural limestone/dolomite for thermochemical energy storage of concentrated solar power. Energy Technol 2016;4(8):1013-9.

[51] Pardo P, Deydier A, Anxionnaz-Minvielle Z, Rougé S, Cabassud M, Cognet P. A review on high temperature thermochemical heat energy storage. Renew Sustain Energy Rev 2014;32:591-610.

[52] Green DW, Perry RH. Perry's chemical engineers' handbook. eighth ed. Mc Graw-Hill; 2007. 
Table 1. Compositional analysis of rice husk ash as determined from XRF (shown as oxides in weight percent).

\begin{tabular}{|r|l|r|l|}
\hline & \% Wt & & $\% \mathbf{W t}$ \\
\hline $\mathbf{A l}_{\mathbf{2}} \mathbf{O}_{\mathbf{3}}$ & 0.07 & $\mathbf{N a}_{\mathbf{2}} \mathbf{O}$ & 0.06 \\
\hline $\mathbf{C a O}$ & 1.90 & $\mathbf{N i O}$ & 0.02 \\
\hline $\mathbf{C r}_{\mathbf{2}} \mathbf{O}_{\mathbf{3}}$ & 0.09 & $\mathbf{P}_{\mathbf{2}} \mathbf{O}_{\mathbf{5}}$ & 0.17 \\
\hline $\mathbf{F e}_{\mathbf{2}} \mathbf{O}_{\mathbf{3}}$ & 0.31 & $\mathbf{S O}_{\mathbf{3}}$ & 0.28 \\
\hline $\mathbf{K}_{\mathbf{2}} \mathbf{O}$ & 0.34 & $\mathbf{S i O}_{\mathbf{2}}$ & 95.8 \\
\hline $\mathbf{M g O}$ & 0.78 & $\mathbf{Z n O}$ & 0.02 \\
\hline $\mathbf{M n O}$ & 0.15 & & \\
\hline
\end{tabular}

Table 2. Porosity data measured by nitrogen adsorption-desorption analysis.

\begin{tabular}{|c|c|c|}
\hline & $\mathbf{7 0 \% C a O}$ & $\mathbf{9 0 \% C a O}$ \\
\hline $\mathbf{S}_{\text {вет }}\left(\mathbf{m}^{2} \mathbf{g}^{-1}\right)$ & 25.0 & 6.6 \\
\hline $\mathbf{V s p}\left(\mathbf{c m}^{3} \mathbf{g}^{-1}\right)$ & 0.074 & 0.027 \\
\hline $\mathbf{W p}(\mathbf{n m})$ & 11.8 & 16.3 \\
\hline Wp BJH (nm) Ads & 17.3 & 25.5 \\
\hline
\end{tabular}




\section{FIGURES}

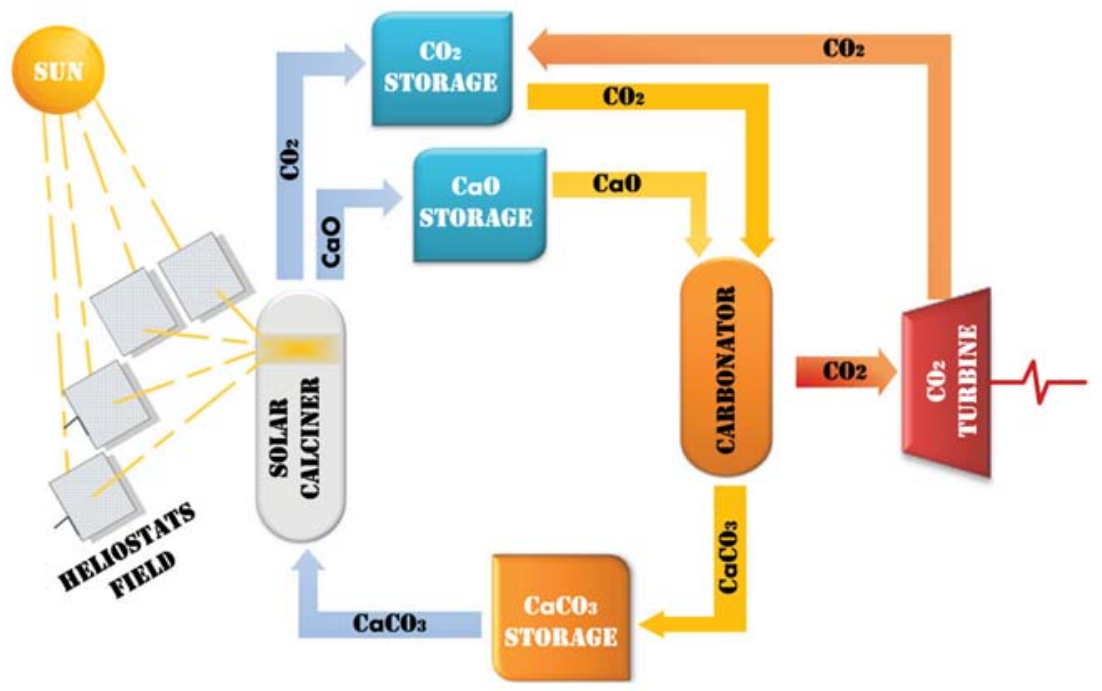

Fig. 1. Flow diagram of the Calcium-Looping thermochemical energy storage system for CSP plants. A detailed energy integration scheme is found in Ref. [14].
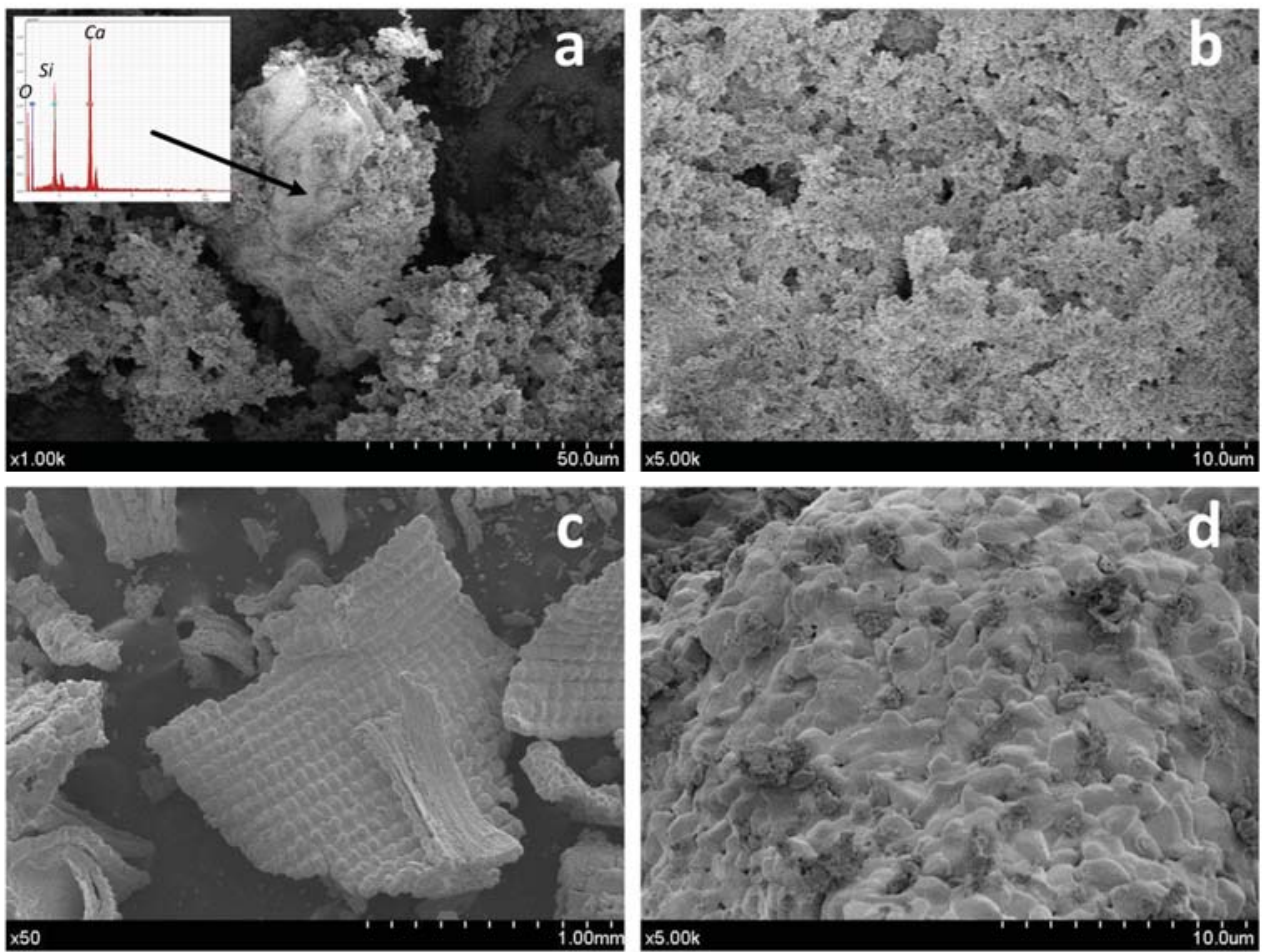

Fig. 2. SEM micrographs of as-prepared $70 \% \mathrm{CaO}$ composite $(\mathrm{a}, \mathrm{b})$ and $90 \% \mathrm{CaO}$ composite (c, d). 

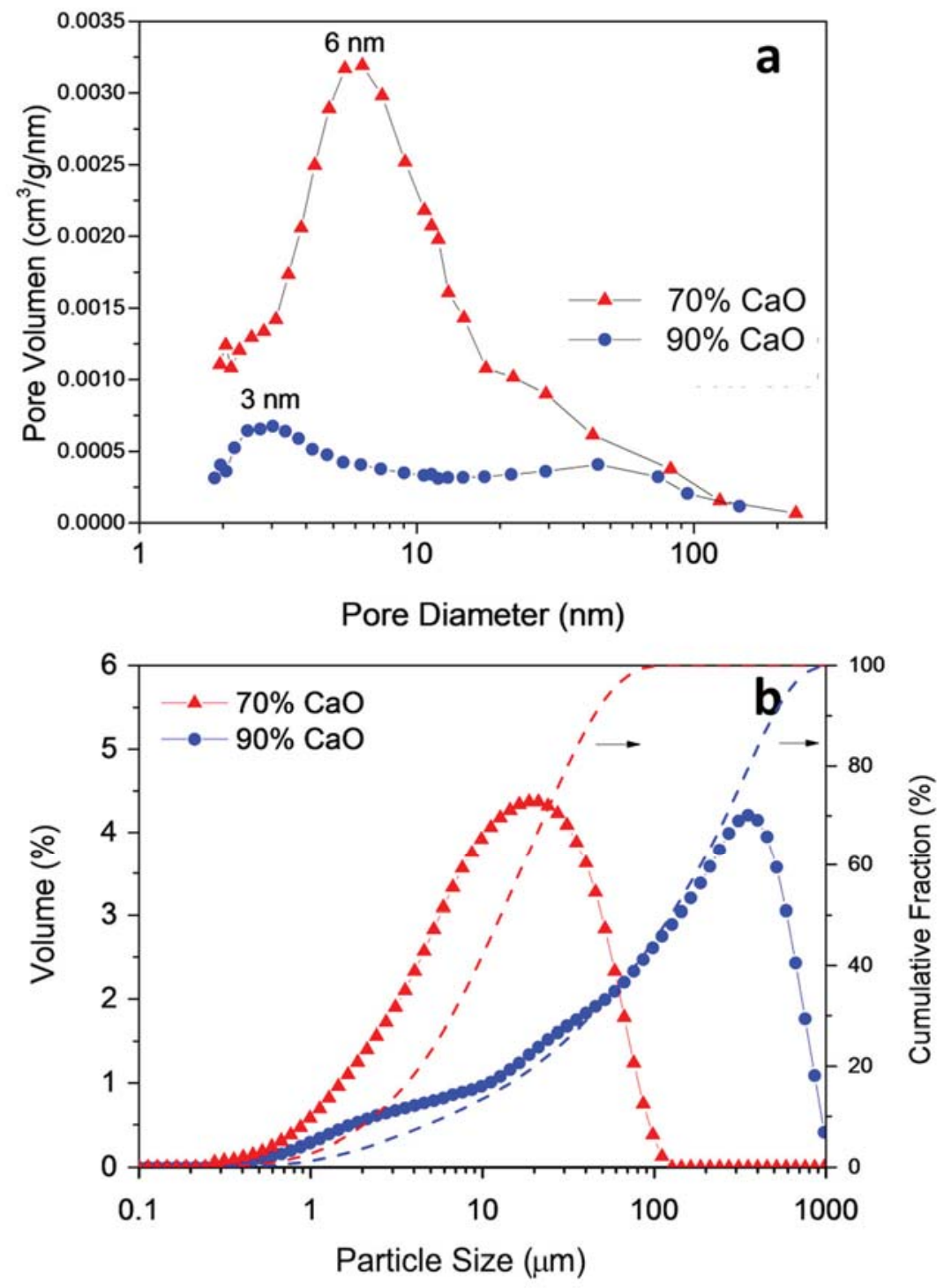

Fig. 3. Pore size distribution $(\mathrm{BJH})(\mathrm{a})$ and particle size frequency and cumulative distributions (b) measured for as-prepared composite materials. 

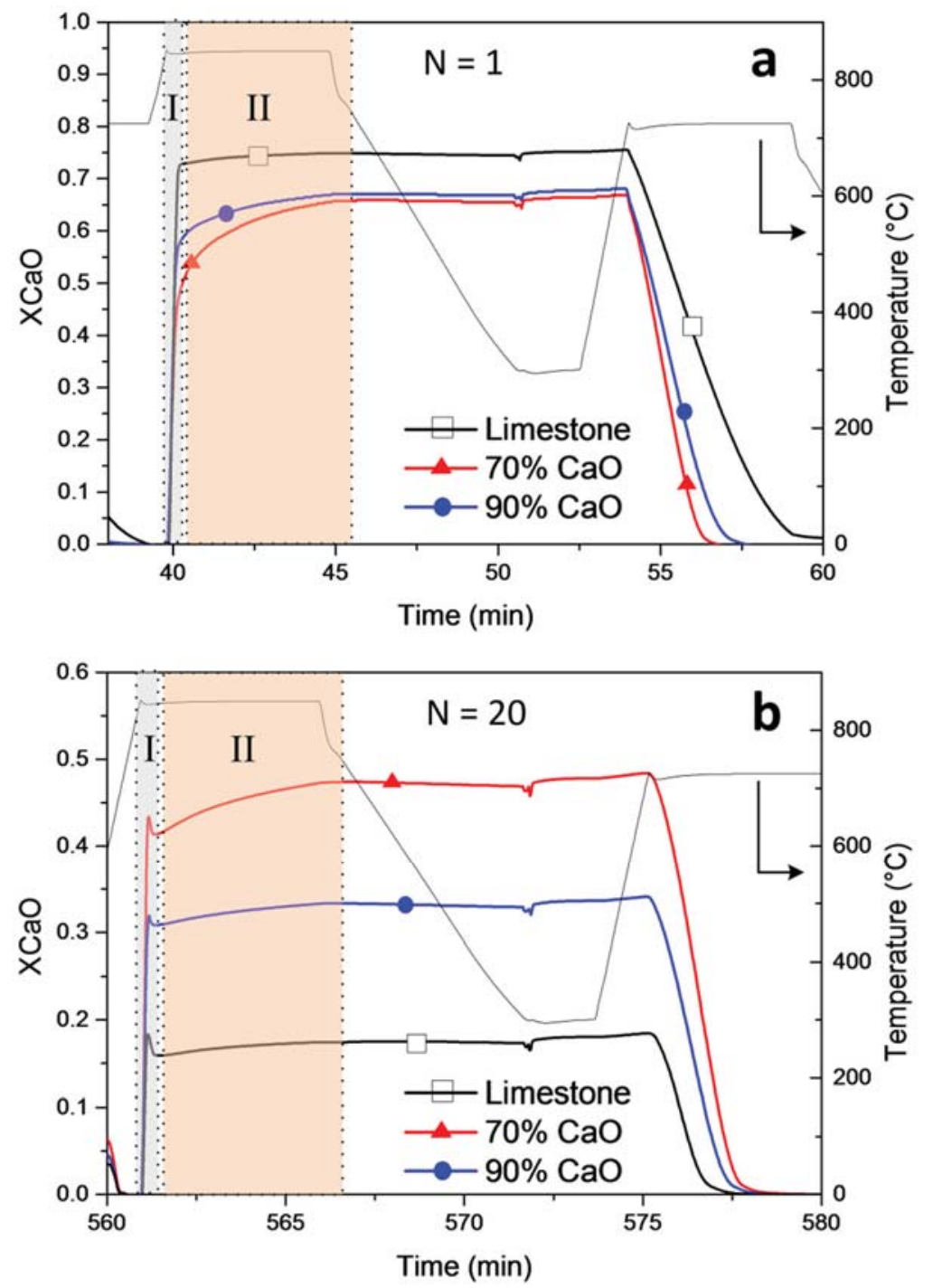

Fig. 4. Time evolution of $\mathrm{CaO}$ conversion and temperature during 1 st (a) and 20 th (b) cycles for the $\mathrm{CaO} / \mathrm{SiO}_{2}$ composites tested under CaL-CSP storage conditions. Colored regions I and II correspond to fast reaction and slow solid-state diffusion controlled phases respectively. 

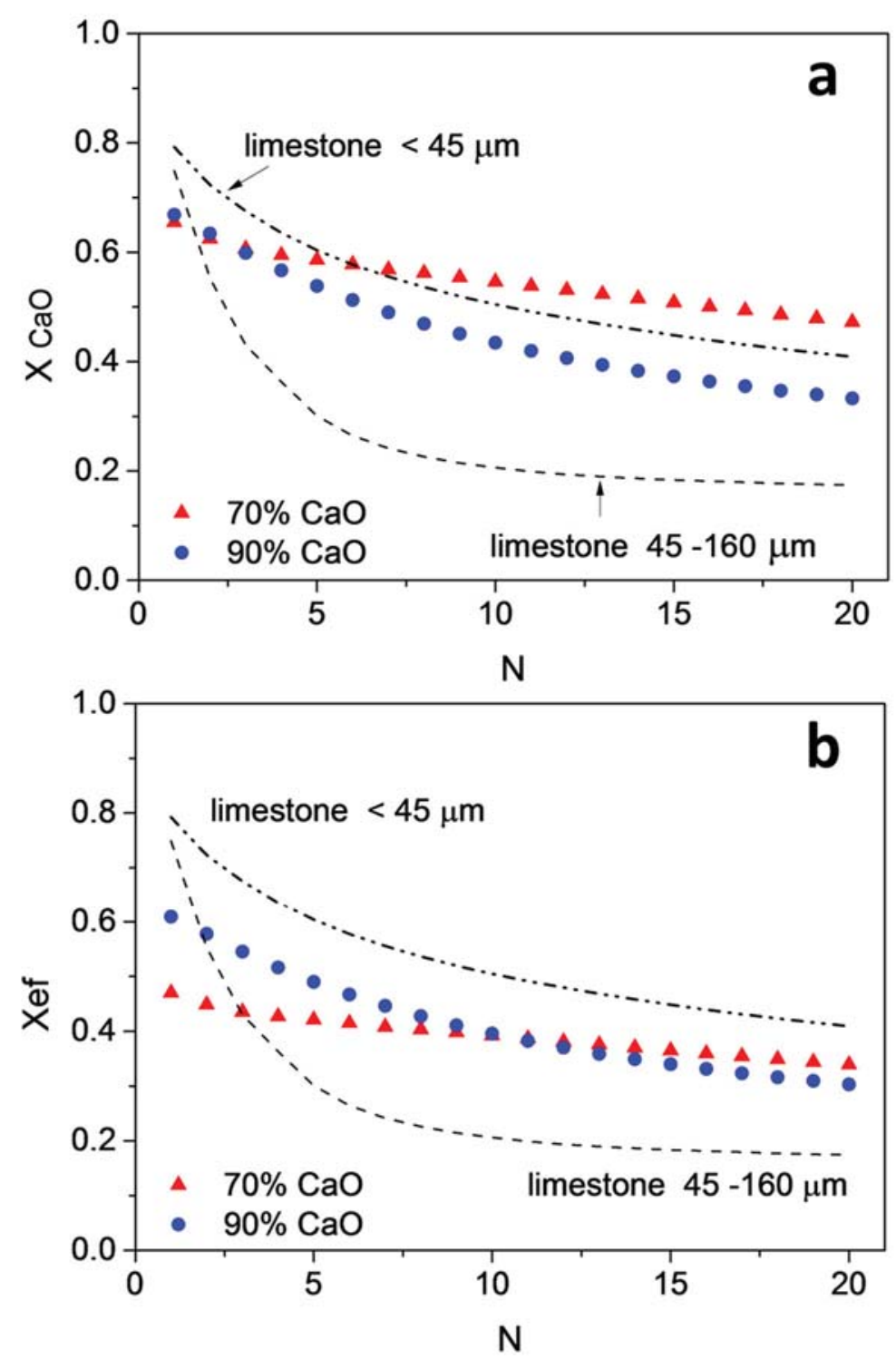

Fig. 5. CaO conversion (a) and effective conversion (b) at the end of the carbonation stage as a function of the cycle number for the $\mathrm{CaO} / \mathrm{SiO}_{2}$ composites tested under CaL CSP storage conditions. Multicycle conversion data for sieved limestone samples reported elsewhere are plotted for comparison. 


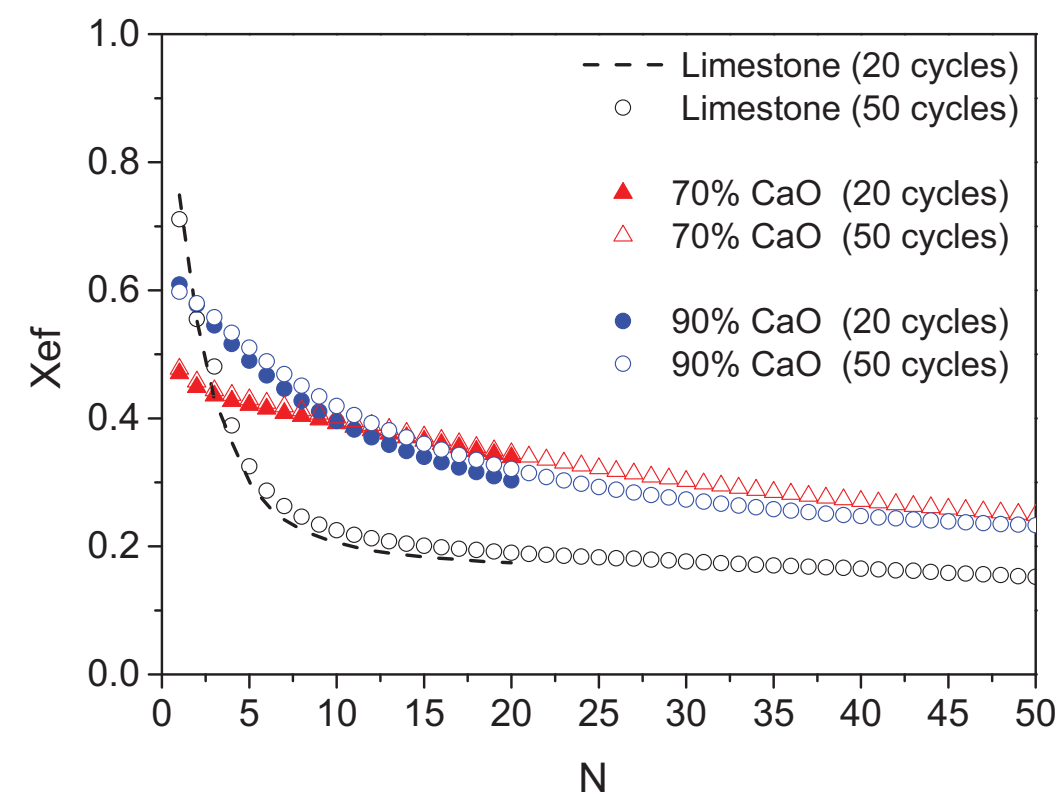

Fig. 6. Effective conversion as a function of the cycle number for both synthetic composites and limestone samples of similar particle size tested under CaL-CSP storage conditions for 20 and 50 cycles.

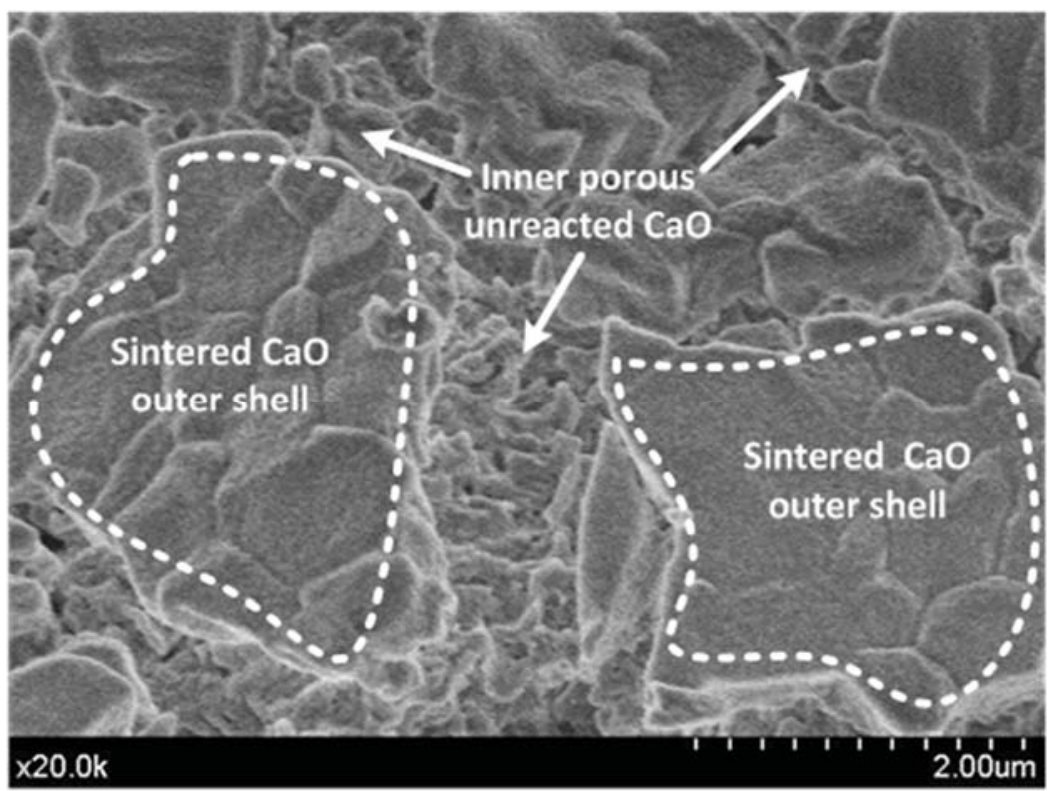

Fig. 7. SEM picture of a limestone sample after $20 \mathrm{CaL}$ cycles ending in calcination and with a broken surface that illustrates a porous inner $\mathrm{CaO}$ skeleton onto which a $\mathrm{CaO}$ sintered layer is formed. 


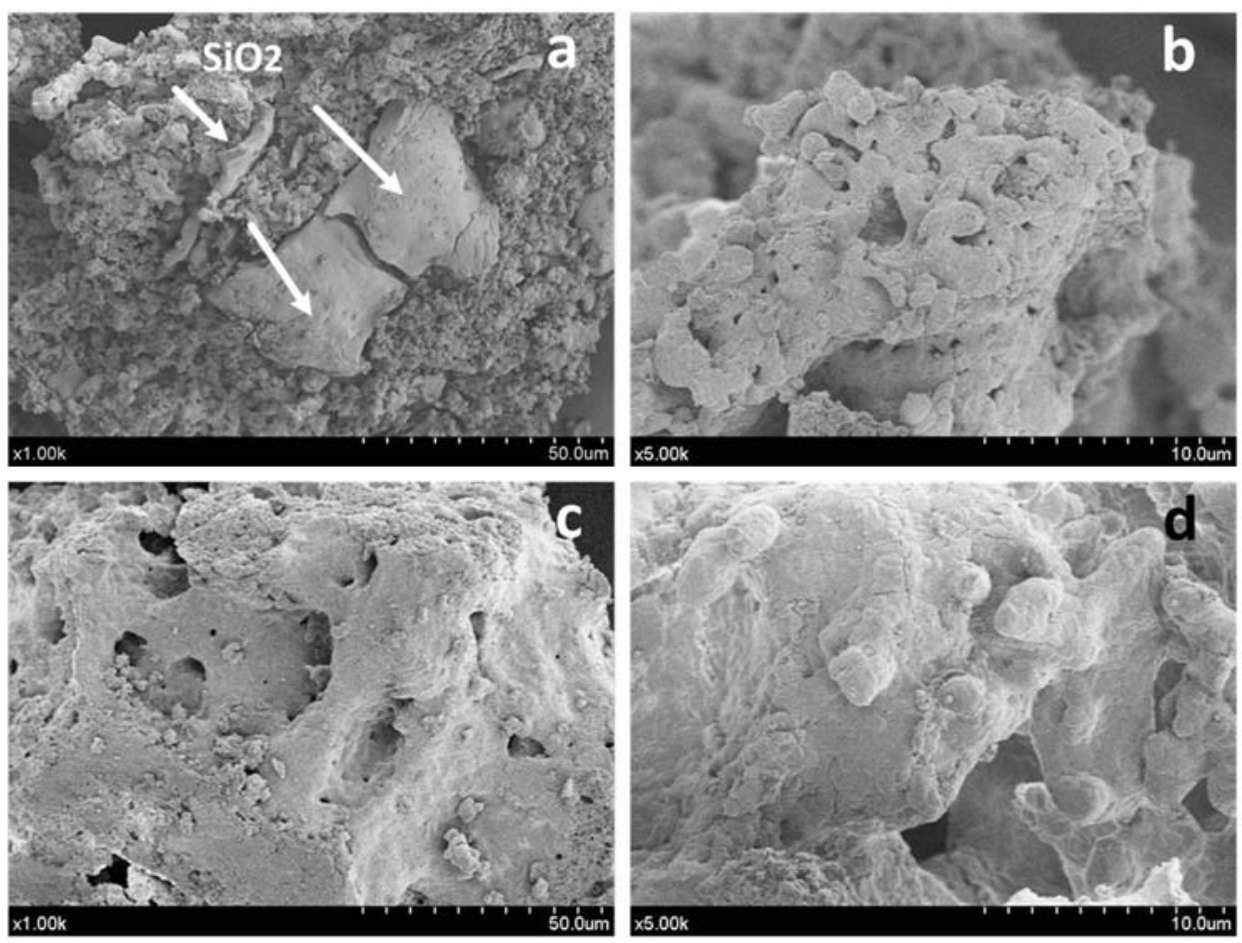

Fig. 8. SEM micrographs of $70 \% \mathrm{CaO}(\mathrm{a}, \mathrm{b})$ and $90 \% \mathrm{CaO}(\mathrm{c}, \mathrm{d})$ composites after 20 CaL cycles.
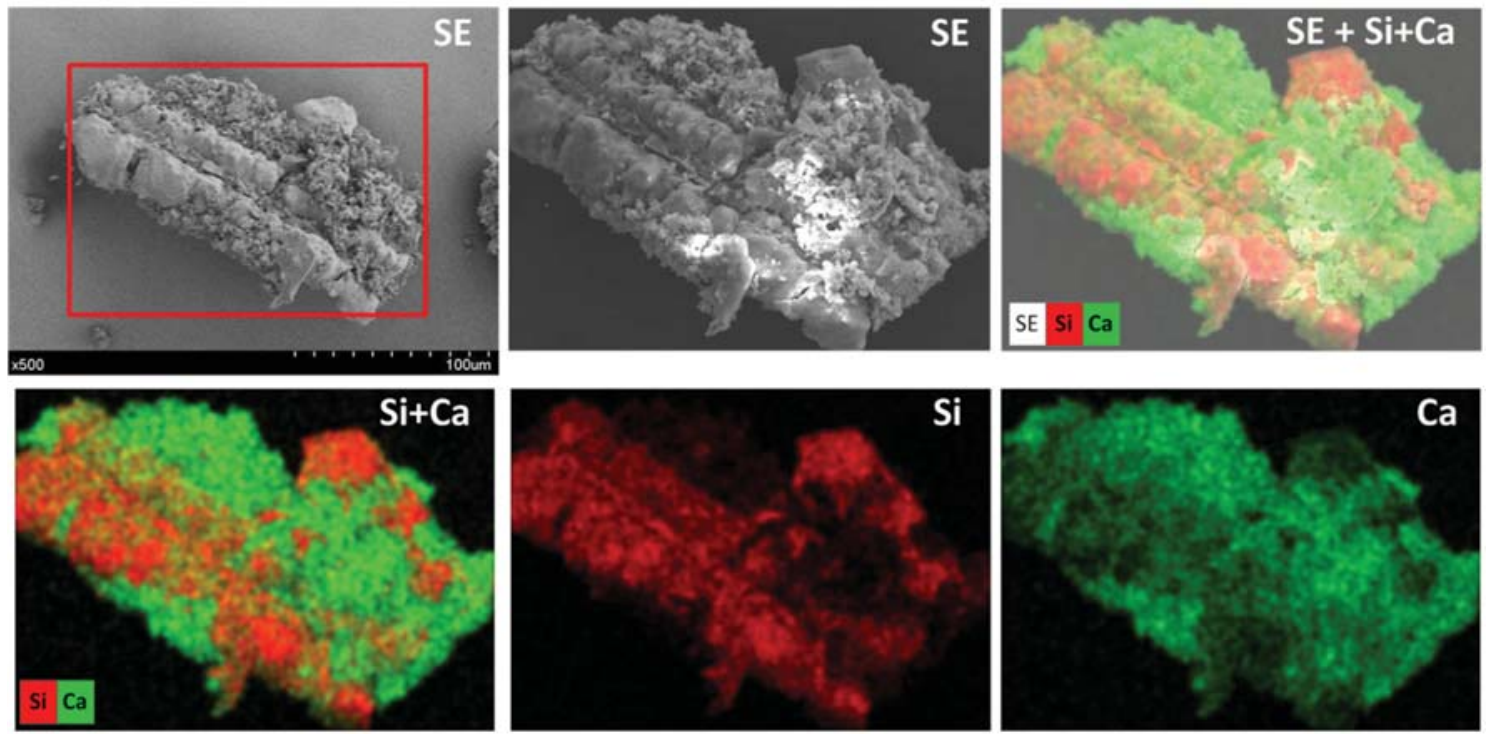

Fig. 9. Secondary electron micrographs (SE at 2 and $20 \mathrm{kV}$ ) and compositional mapping ( $\mathrm{Ca}$ and $\mathrm{Si}$ ) of the $70 \% \mathrm{CaO}$ composite sample after $20 \mathrm{CaL}$ cycles. 

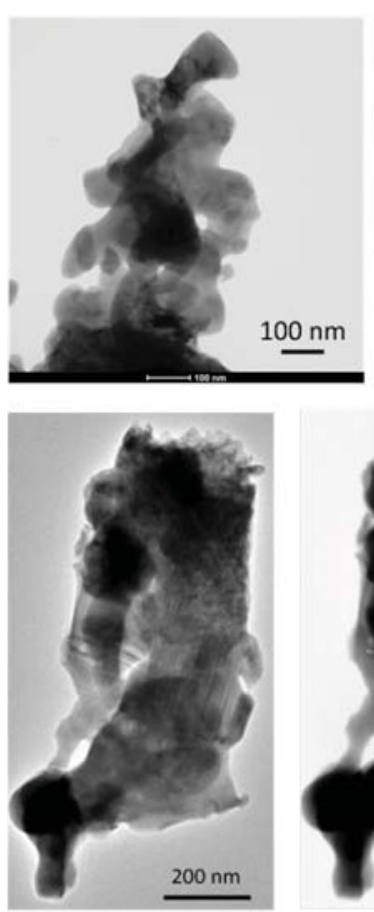
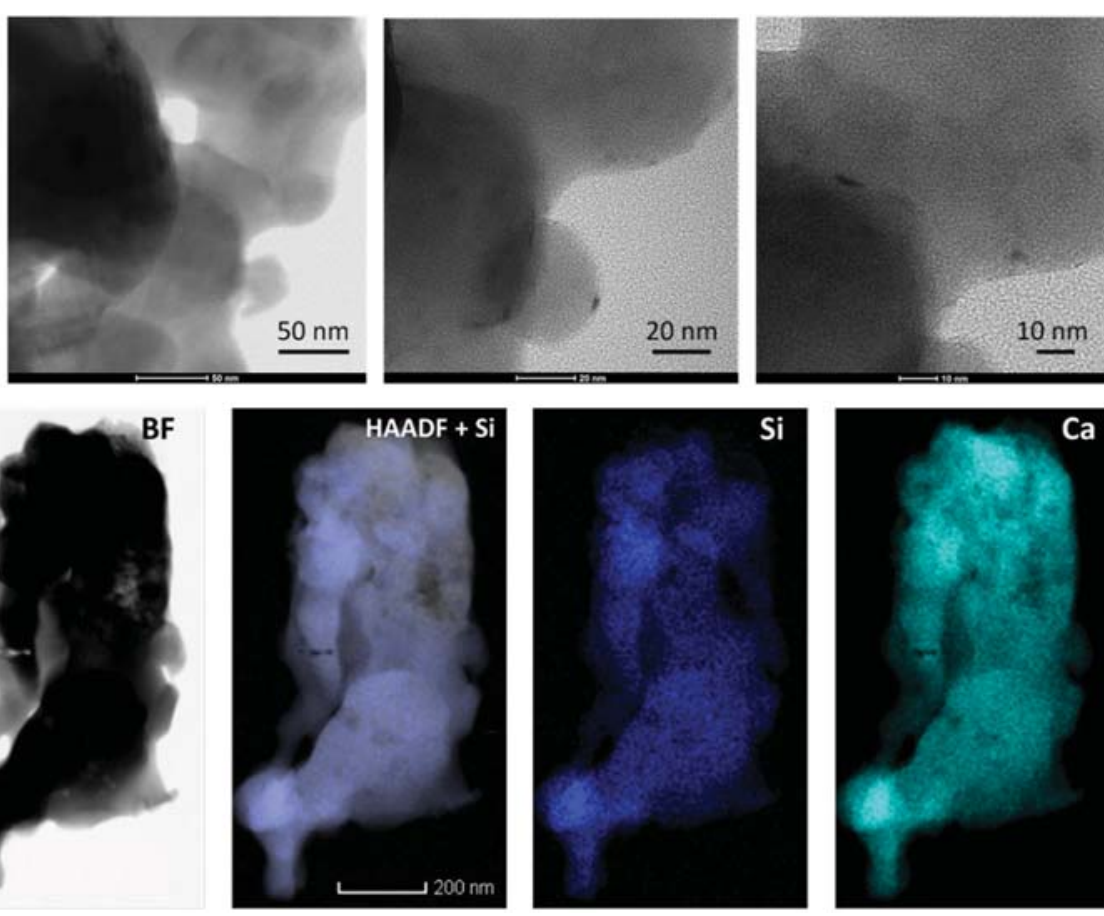

Fig. 10. HRTEM micrographs and HAADF-STEM mapping for $\mathrm{Si}$ and $\mathrm{Ca}$ elements of $70 \% \mathrm{CaO}$ composite after being subjected to 20 cycles under CaL-CSP conditions.

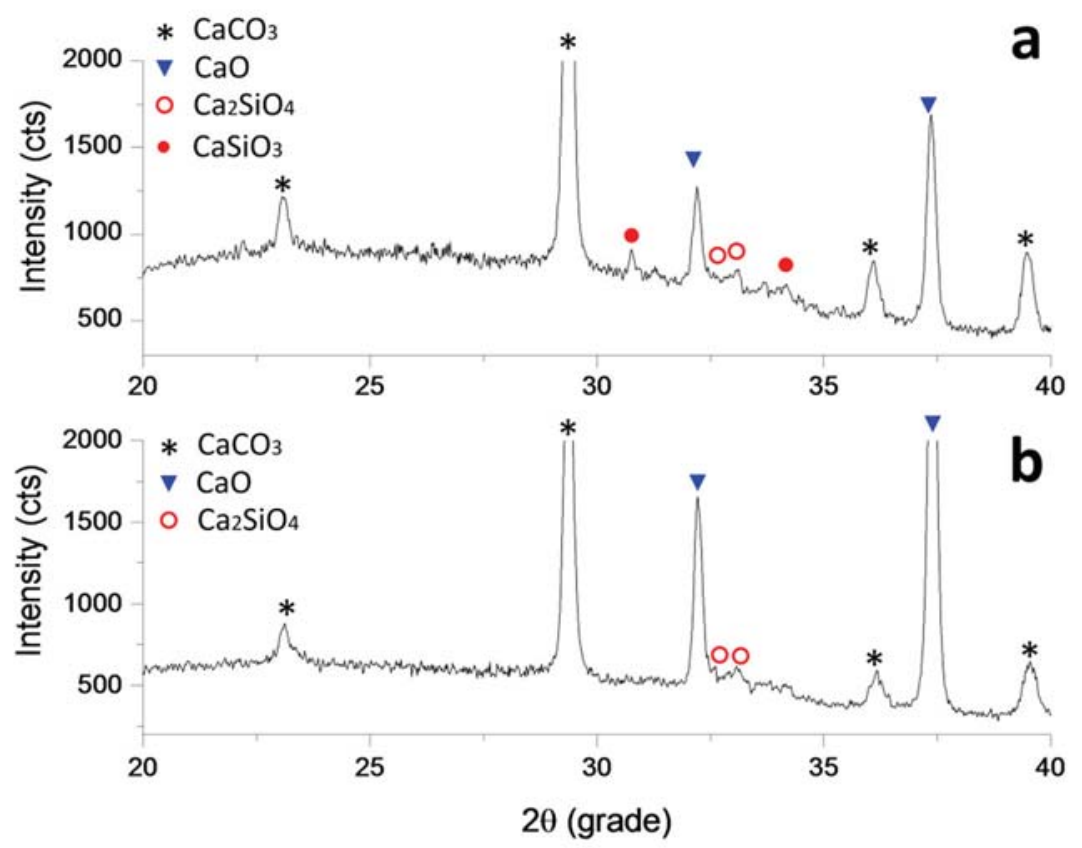

Fig. 11. XRD patterns recorded for the $70 \% \mathrm{CaO}$ (a) and $90 \% \mathrm{CaO}$ (b) samples after being cycled. 


\section{Appendix (Supplementary Content):}

\section{Pretreatment of Rice Husk and Synthesis of Rice Husk Ash}

In our work raw rice husk was pretreated to be used as template. First, rice husk was ground to $1 \mathrm{~mm}$ (centrifugal blade-mill, Retsch ZM1). Afterwards, the milled husk was washed in distilled boiling water for 2 hours. The washing process was repeated twice after water replacement. Finally, the husk was oven-dried at $120^{\circ} \mathrm{C}$. SEM micrographs of pretreated rice husk are shown in Fig. A3. This pretreatment ensures the removal of alkali elements [40], and the obtention of high purity nanostructured $\mathrm{SiO}_{2}$ of large specific surface area.

In order to characterize and quantify the ash content, pretreated rice husk was thermally treated. Rice husk ash was obtained following two steps thermal treatment in which pyrolysis and combustion take place separately to attain large surface area. A first pyrolysis stage was carried out under nitrogen atmosphere at a heating rate of $3{ }^{\circ} \mathrm{C} \mathrm{min}^{-1}$ from ambient temperature to $600{ }^{\circ} \mathrm{C}$, which was kept for $3 \mathrm{~h}$. This produces an amorphous carbon skeleton and inorganic ash. The second stage consists of combustion at $600{ }^{\circ} \mathrm{C}$ under air for $3 \mathrm{~h}$ to remove the carbonaceous char as was inferred from TG/DSC observations (Fig. A4). A quantity of $1.5 \mathrm{~g}$ of pretreated rice husk was subjected to this thermal treatment in a tubular oven using a flow rate of $100 \mathrm{mLmin}^{-1}$. The weight of the residual inorganic ash obtained corresponds to $11 \%$ of the initial raw sample weight (mean value from three independent runs). Composition, microstructure and specific surface area of the synthesized rice husk ash were analyzed using $X R F, X R D, S E M, H R T E M$ and $\mathrm{N}_{2}$ adsorption-desorption isotherms, described in the experimental section. 
Additional Figures:
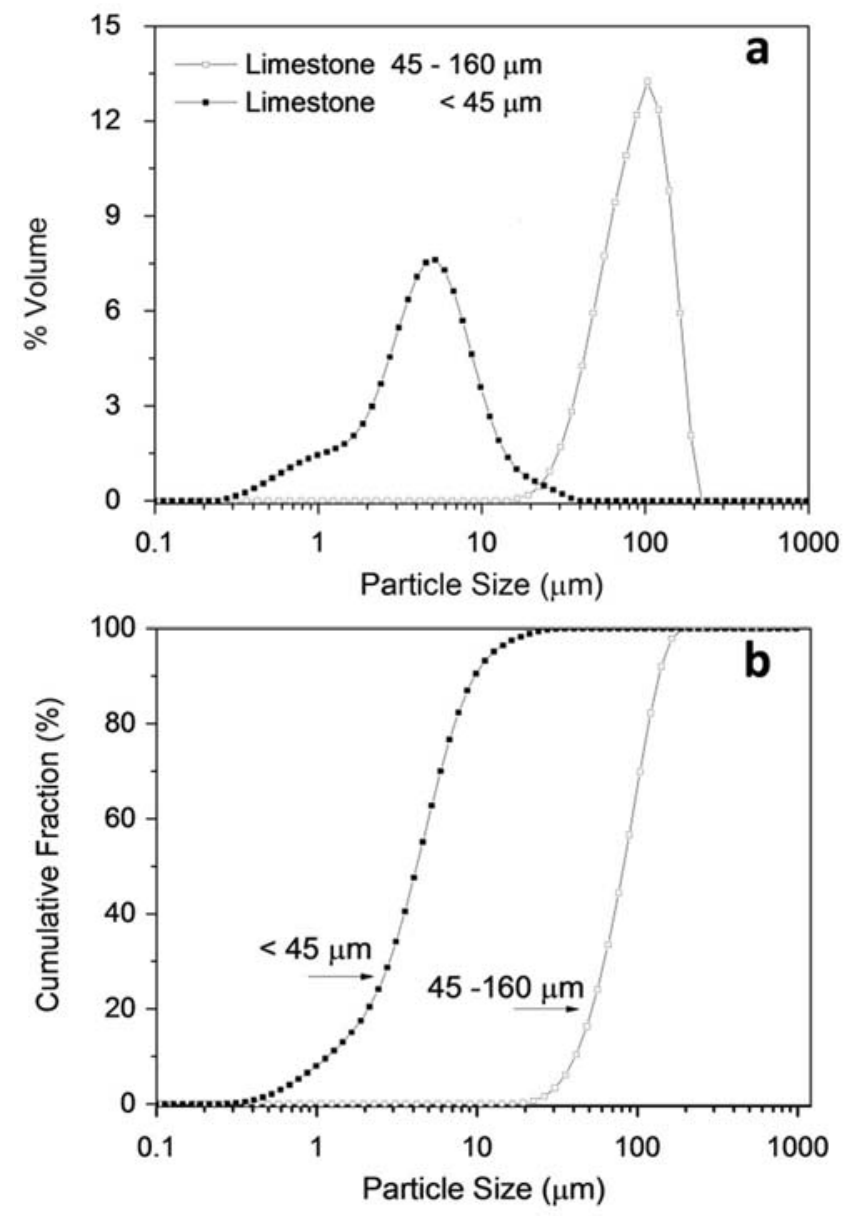

Fig.A1. PSD of limestone samples sieved $<45$ microns and 45-160 microns. 


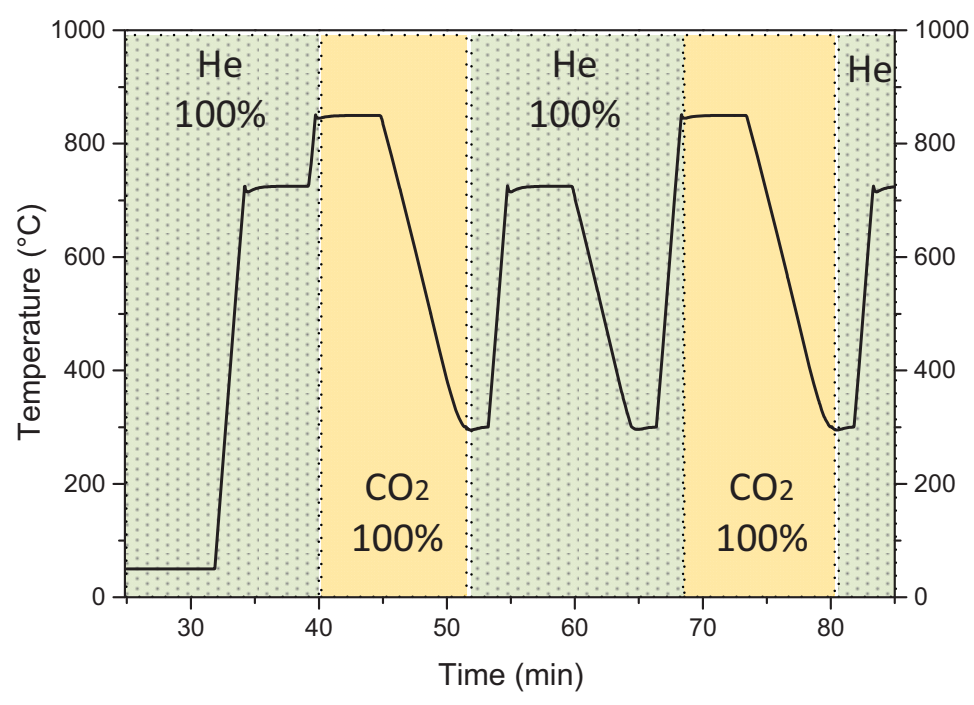

Fig.A2. Schematic representation of the temperature program carried out to test the multicycle performance of the synthesized $\mathrm{CaO}-\mathrm{SiO}_{2}$ composites under CaL-CSP conditions using a Q5000IR thermogravimetric analyzer (TA Instruments). The colored regions indicate the gas atmosphere employed in each calcination/carbonation step.
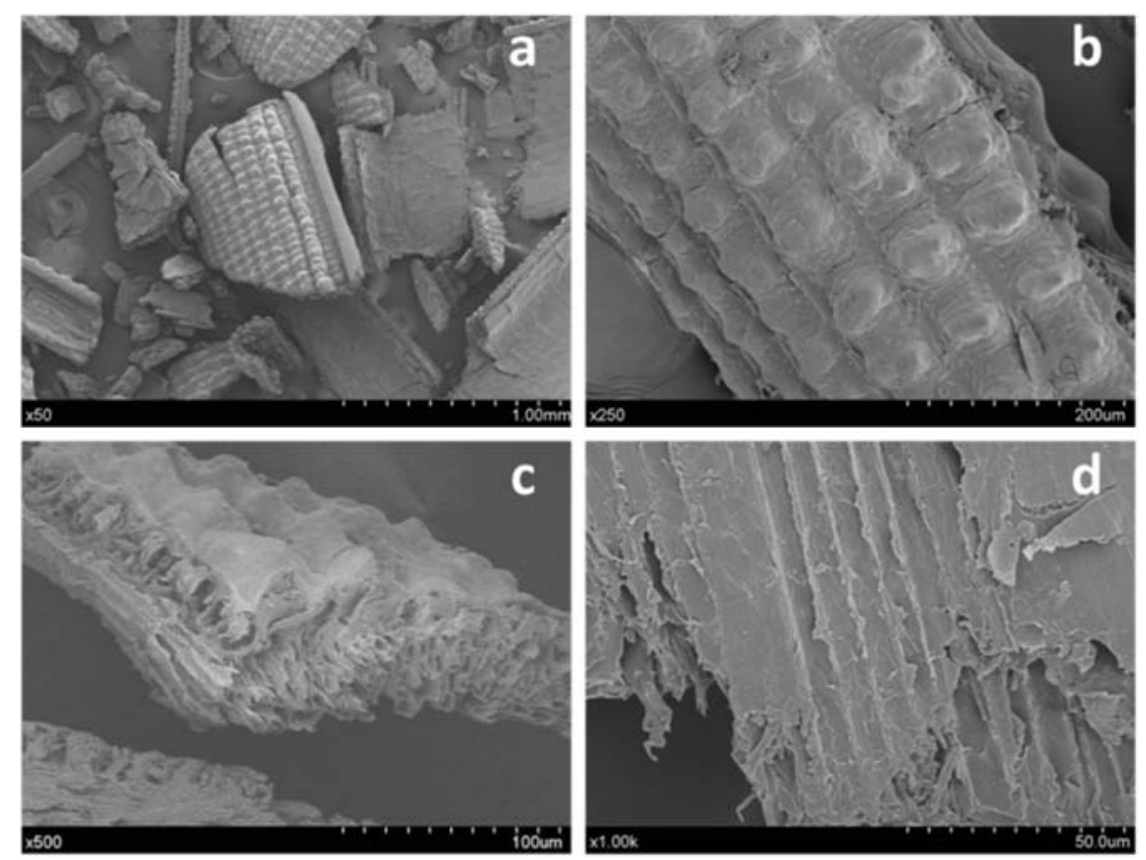

Fig. A3. SEM micrographs of the biotemplate prepared in this work by milling, hot-washing and drying rice husk as detailed in the experimental section. 


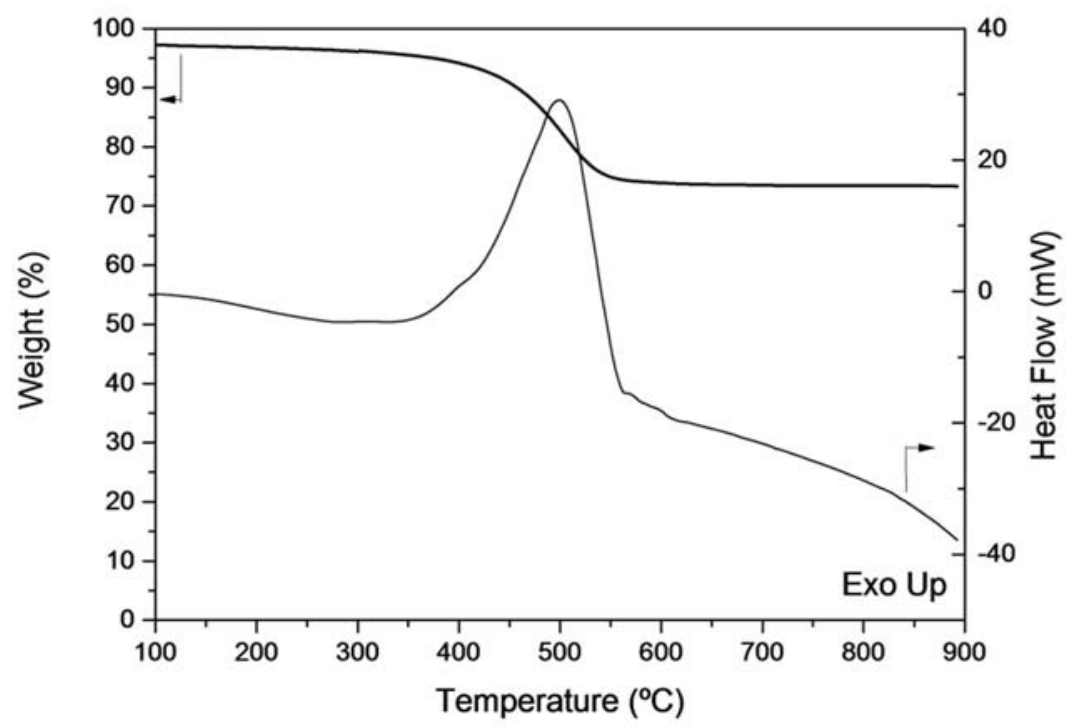

Fig. A4. Thermogravimetry and differential scanning calorimetry of pre-pyrolyzed rice husk under TG/DSC was conducted using a SDT Q600 (TA Instruments) in the temperature range $25-900{ }^{\circ} \mathrm{C}$ and using a heating ramp of $10^{\circ} \mathrm{C} \mathrm{min}-1$ under an air flow rate of $100 \mathrm{~mL} \mathrm{~min}{ }^{-1} .10 \mathrm{mg}$ sample was employed.
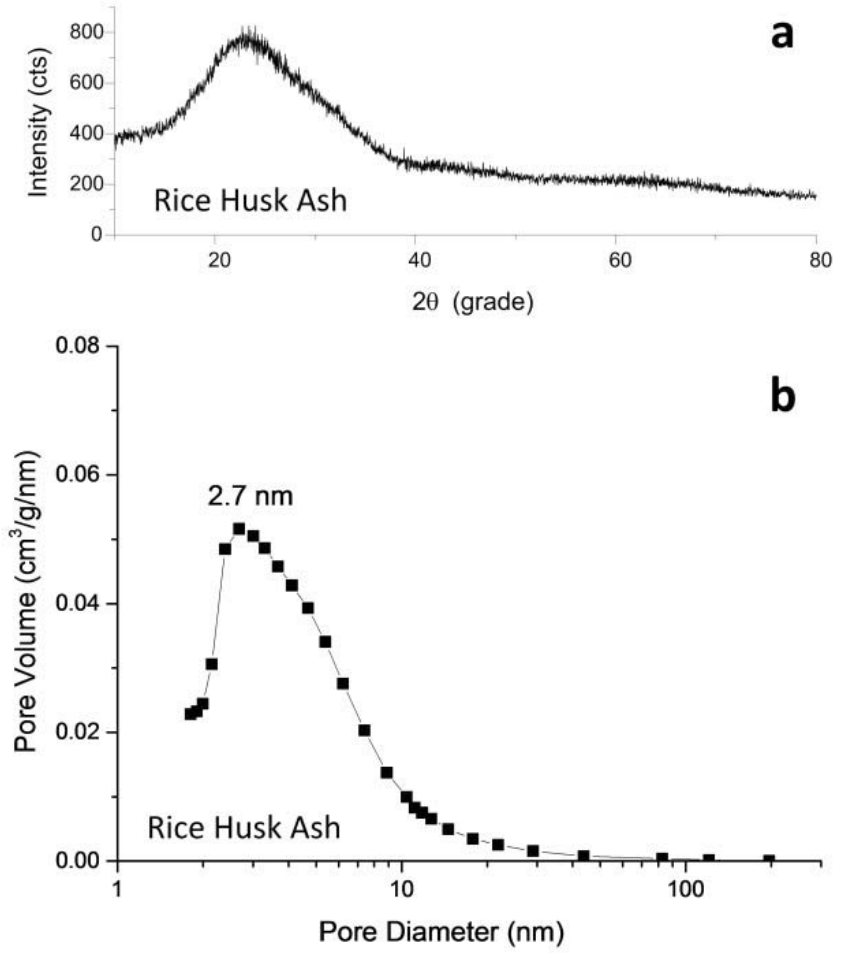

Fig.A5. Powder X-Ray diffractogram (a) and BJH pore size distribution (b) of rice husk ash. 

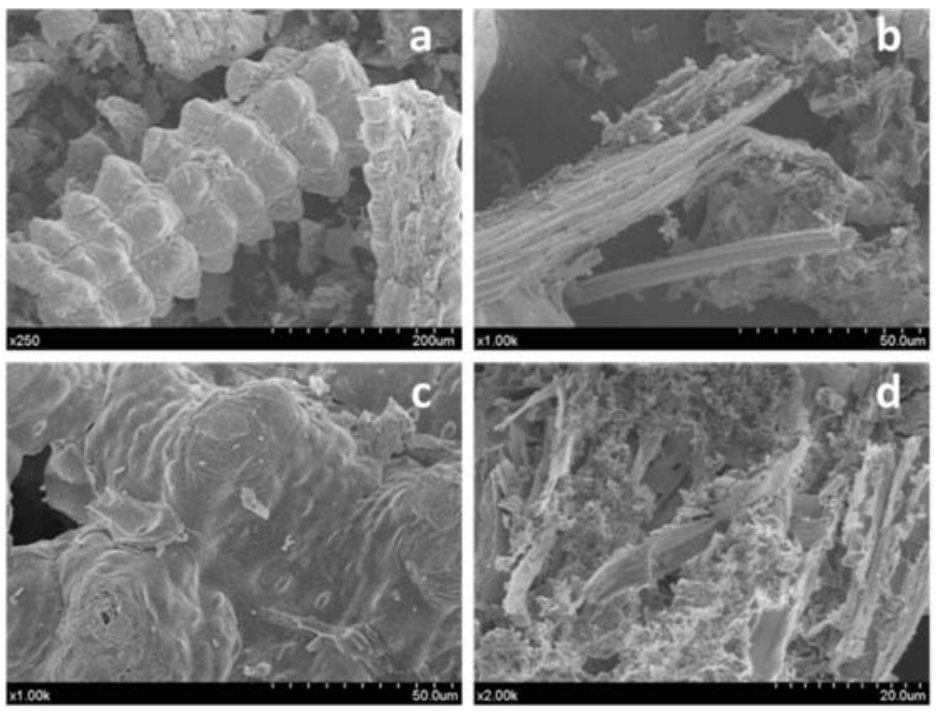

Fig. A6. SEM micrographs of rice husk ash
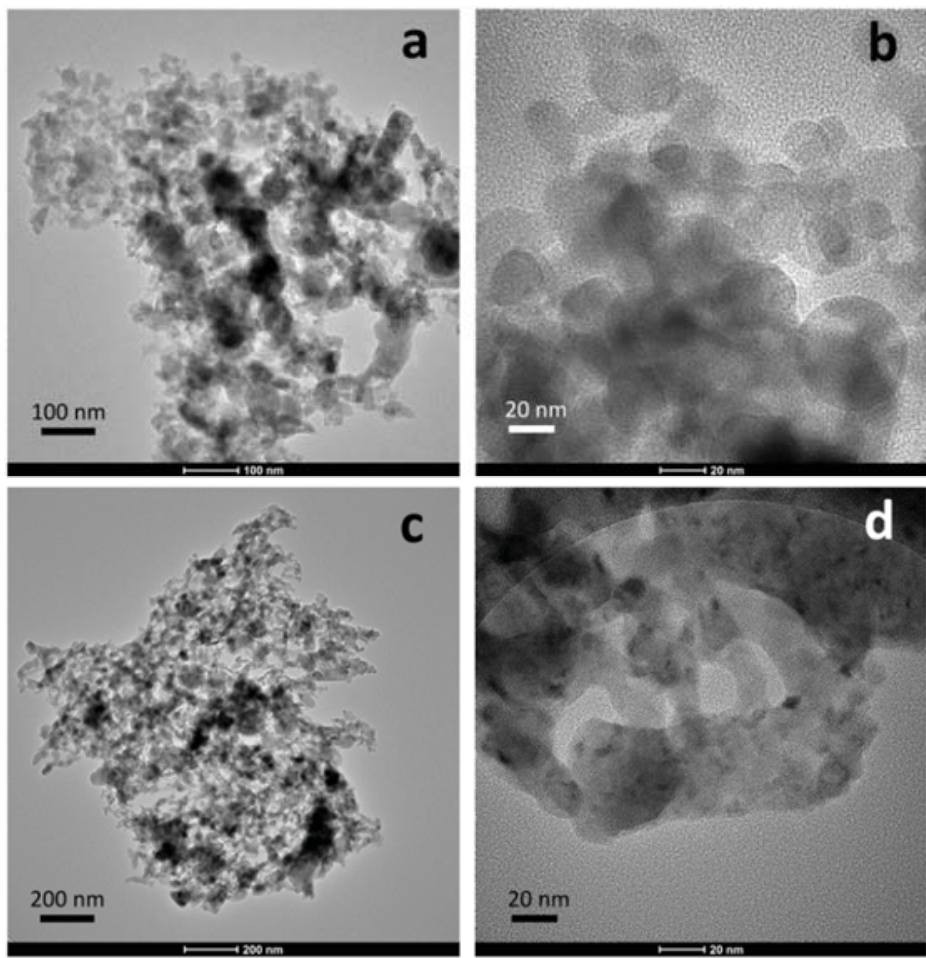

Fig. A7. TEM micrographs of rice husk ash 


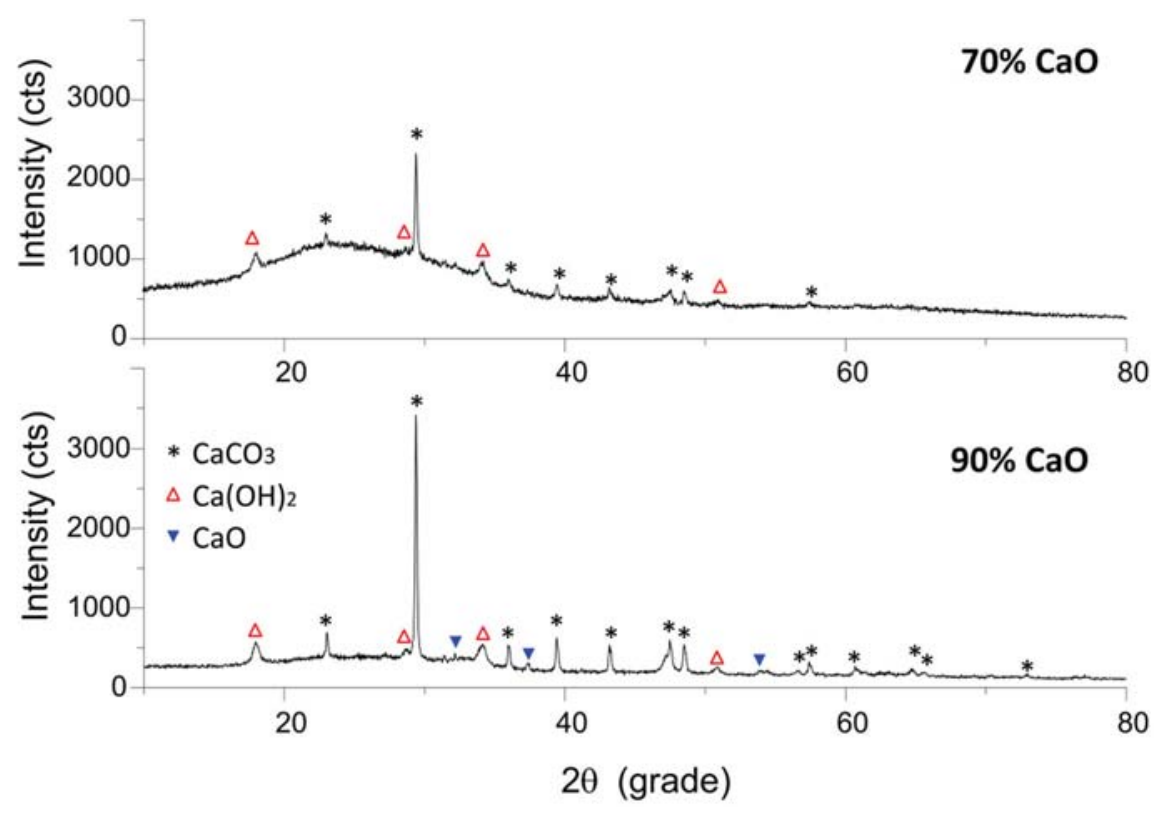

Fig. A8. Powder X-ray diffractograms of as-prepared composites with different $\mathrm{CaO}$ loads.

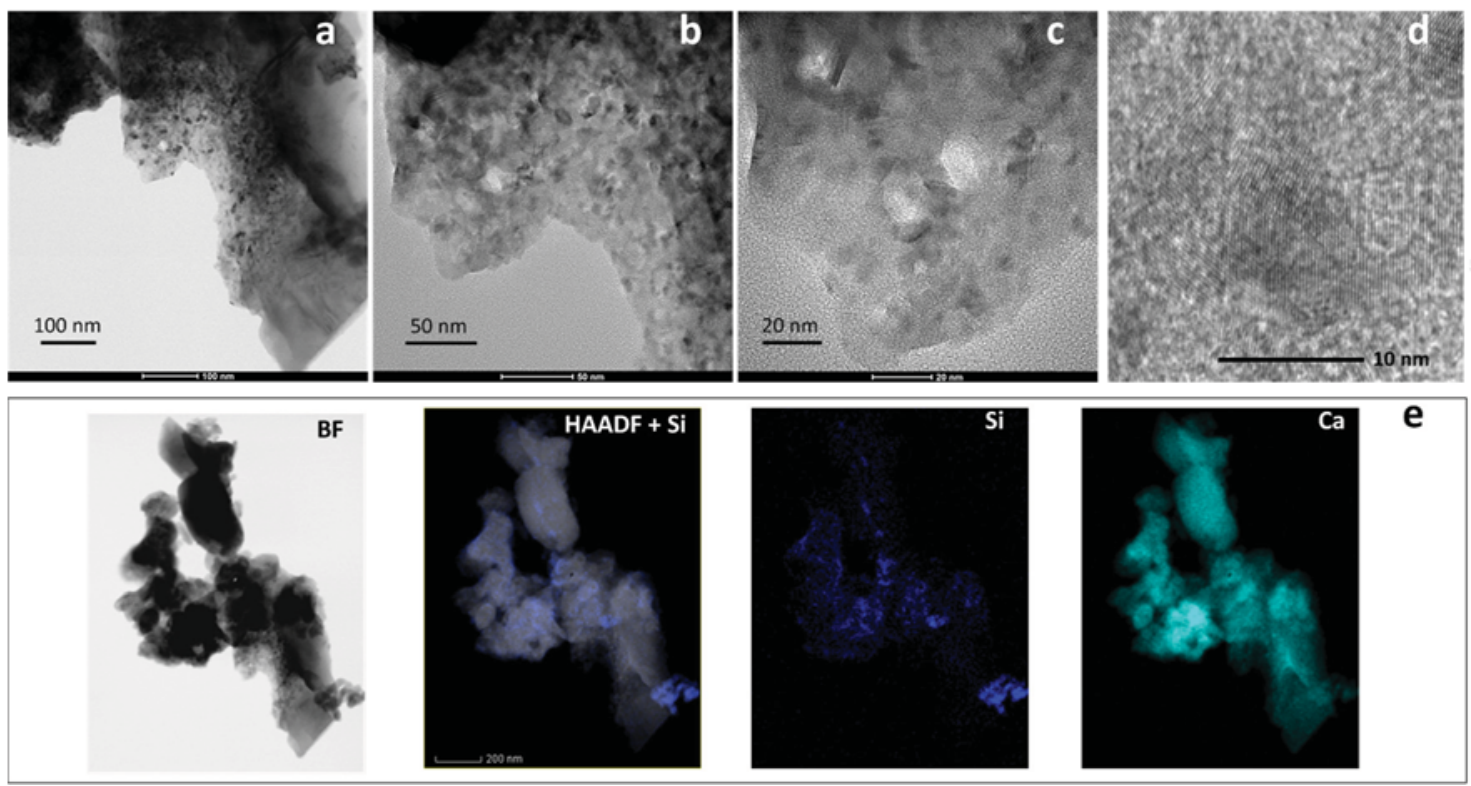

Fig. A9. HRTEM micrographs (a-d) and HAADF-STEM mapping for $\mathrm{Si}$ and $\mathrm{Ca}$ elements (e) of as-prepared $70 \% \mathrm{CaO}$ composite. 

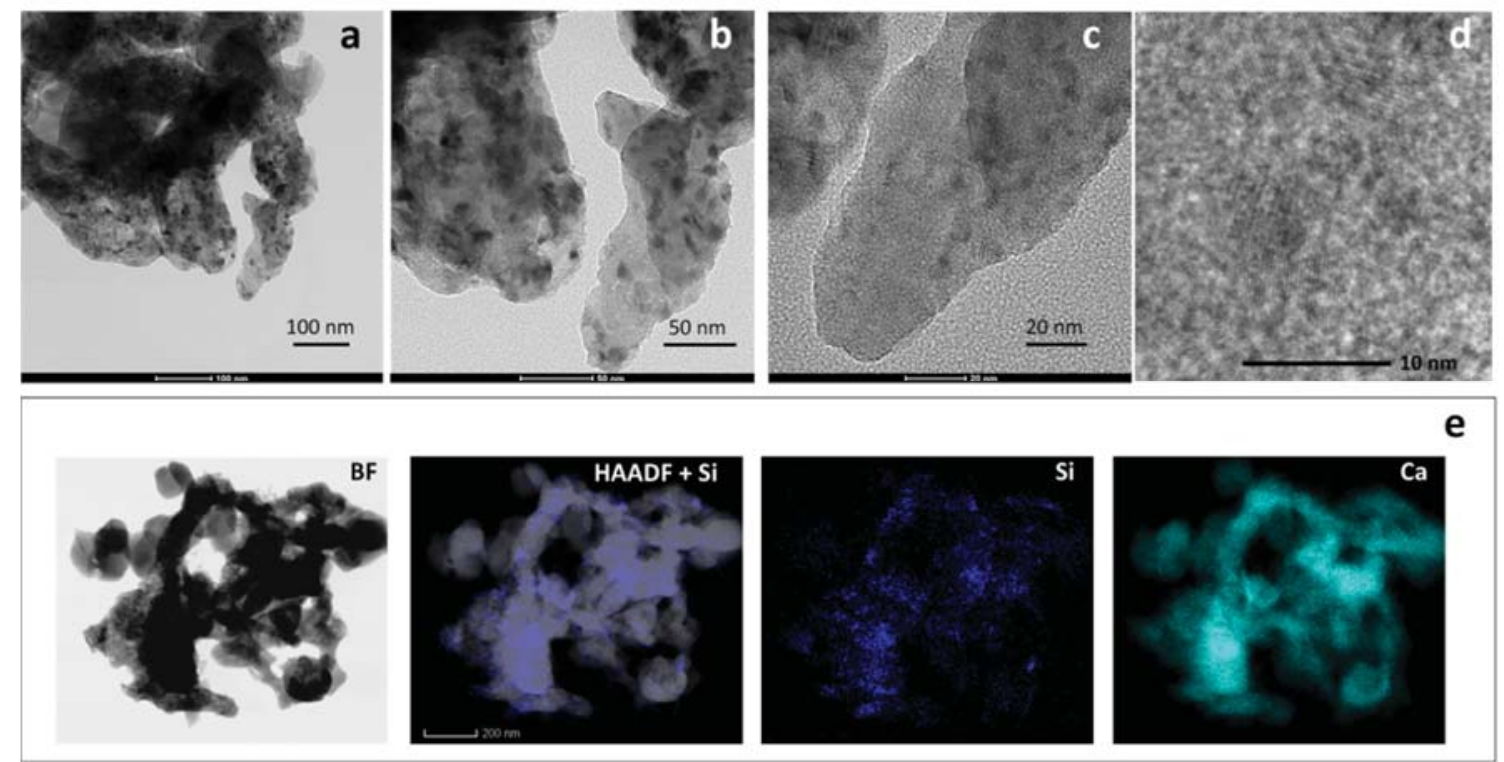

Fig.A10. HRTEM micrographs (a-d) and HAADF-STEM mapping for Si and $\mathrm{Ca}$ elements (e) of as-prepared $90 \% \mathrm{CaO}$ composite.
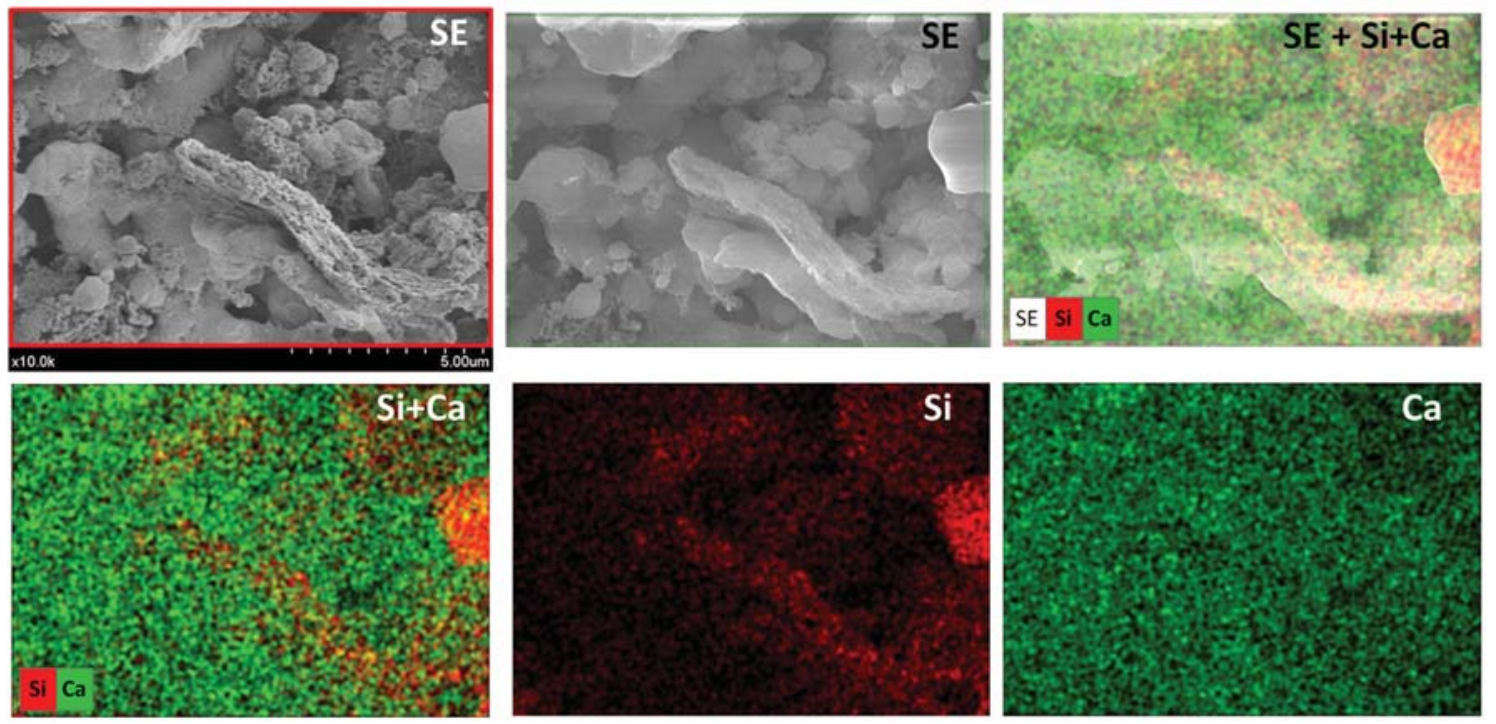

Fig.A11. Secondary electron micrographs (SE at 2 and 20kV) and compositional mapping ( $\mathrm{Ca}$ and $\mathrm{Si}$ ) of $70 \% \mathrm{CaO}$ composite after being subjected to 20 cycles under CaL-CSP conditions. 

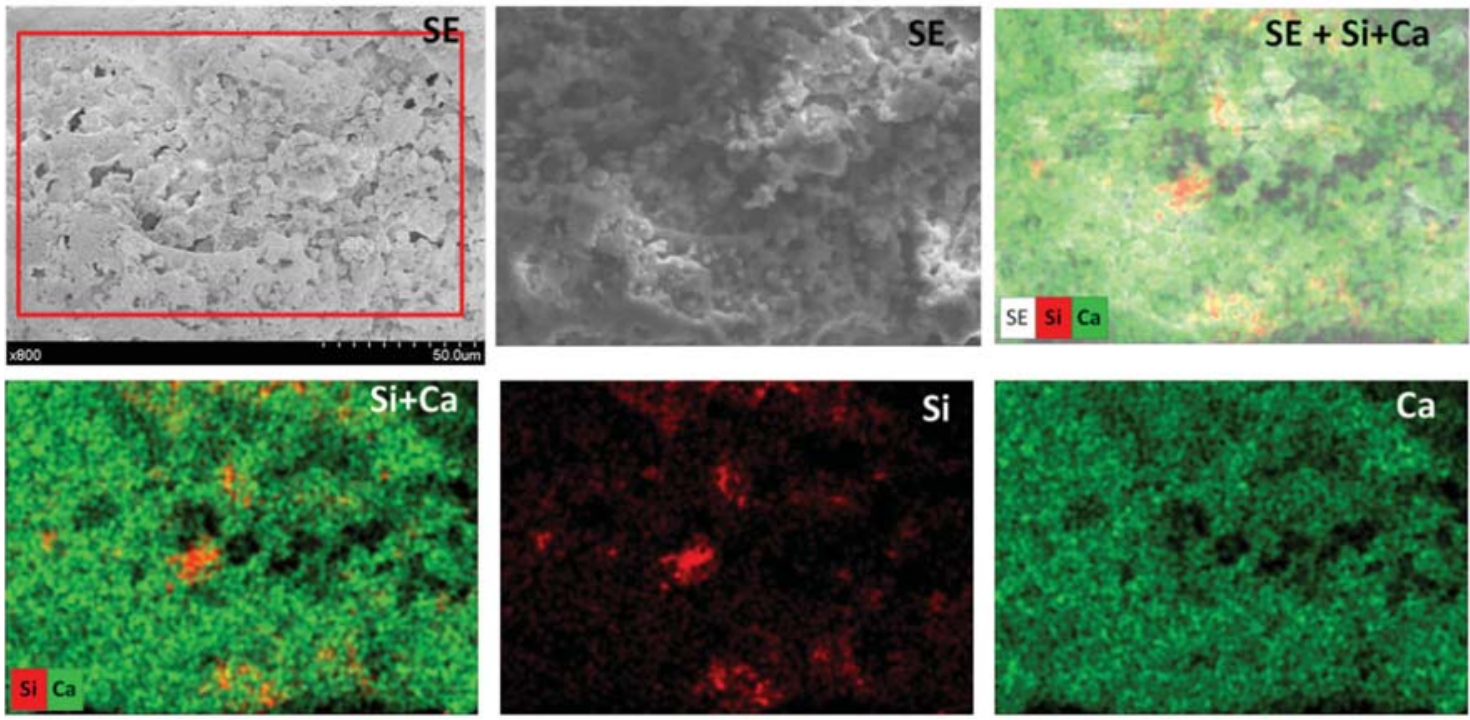

Fig.A12. Secondary electron micrographs (SE at 2 and 20kV) and compositional mapping ( $\mathrm{Ca}$ and $\mathrm{Si}$ ) of $90 \% \mathrm{CaO}$ composite after being subjected to 20 cycles under CaL-CSP conditions.
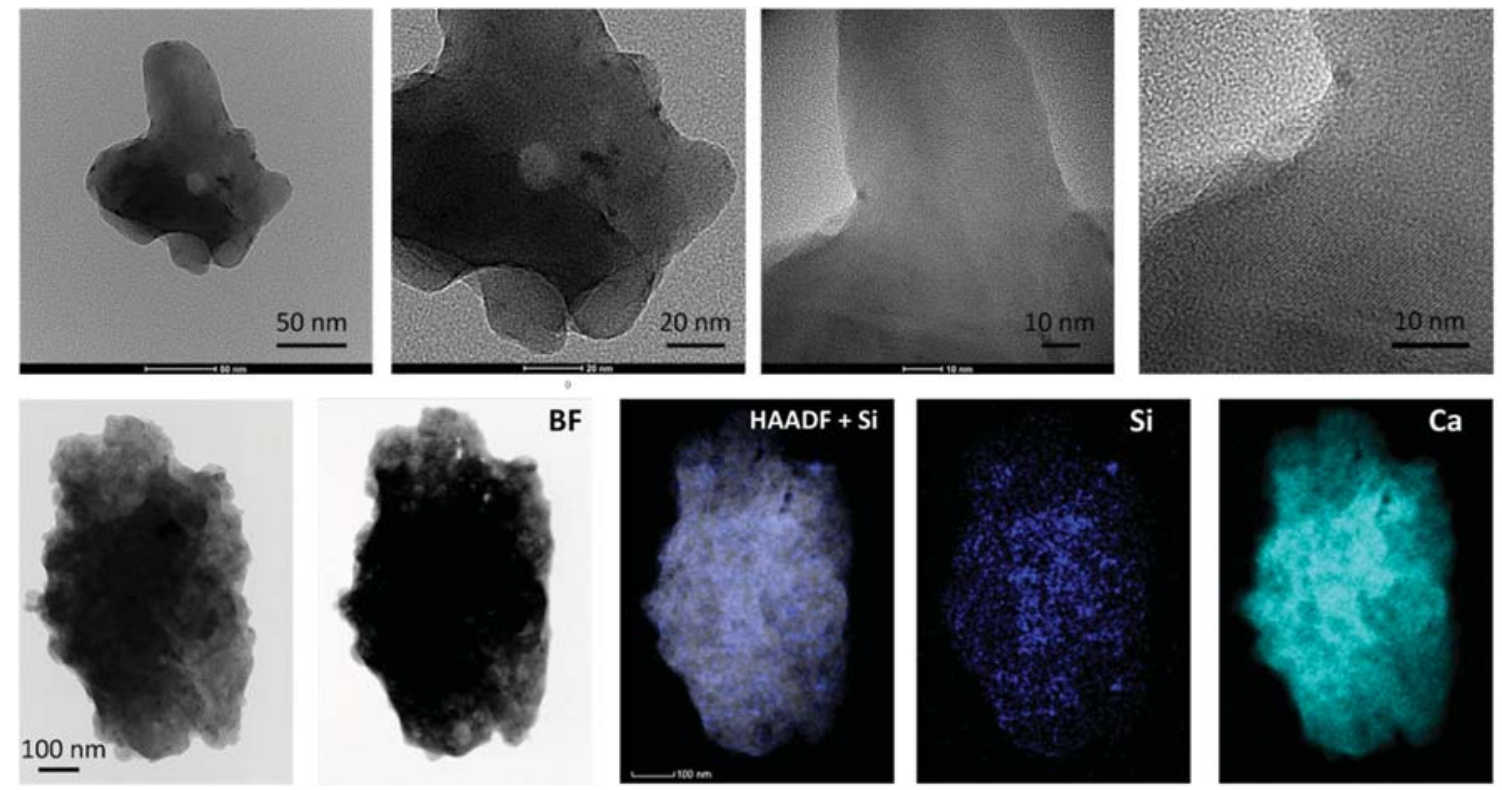

Fig. A13. HRTEM micrographs and HAADF-STEM mapping for $\mathrm{Si}$ and $\mathrm{Ca}$ elements of the $90 \% \mathrm{CaO}$ composite sample after 20 cycles. 